\title{
Ectopic FGF23 production induces mineral changes, osteogenic transdifferentiation, and cancer associated microcalcifications
}

Ida Marie Boisen ${ }^{1,2}$, John Erik Nielsen ${ }^{3}$, Ireen Kooij ${ }^{1}$, Jovana Kaludjerovic ${ }^{2}$, Peter J. O'Shaughnessy ${ }^{4}$, Peter W. Andrews ${ }^{5}$, Noriko Ide ${ }^{2}$, Birgitte Grønkær Toft ${ }^{6}$, Anders Juul ${ }^{3}$, Lee B. Smith7, Richard W. Norman ${ }^{8}$, Ewa Rajpert-De Meyts ${ }^{3}$, Beate Lanske², Martin Blomberg Jensen ${ }^{1,2 *}$

1: Group of Skeletal, Mineral, and Gonadal Endocrinology, Department of Growth and Reproduction, Rigshospitalet, University of Copenhagen, DK-2100 Copenhagen, Denmark

2: Division of Bone and Mineral Research, Harvard School of Dental Medicine/Harvard Medical School, Harvard University, Boston, MA 02108, US

3: Department of Growth and Reproduction, Rigshospitalet, University of Copenhagen, DK-2100 Copenhagen, Denmark

4: College of Medical, Veterinary and Life Sciences, Institute of Biodiversity, Animal Health and Comparative Medicine, University of Glasgow, G61 1QH, Glasgow, UK

5: Centre for Stem Cell Biology, Department of Biomedical Science, University of Sheffield, Western Bank, Sheffield S10 2TN, UK

6: Department of Pathology, Rigshospitalet, DK-2100 Copenhagen, Denmark

7: MRC Centre for Reproductive Health, University of Edinburgh, The Queen's Medical Research Institute, 47 Little France Crescent, Edinburgh, EH16 4TJ, UK

8: Department of Urology, Dalhousie University, Halifax, Nova Scotia, Canada

Keywords: FGF23, microcalcifications, cancer, reproduction, testis

Abstract: 307 words

Word count: 3897

Figures: 6

Tables: 0

*Address for correspondence

Martin Blomberg Jensen

Blombergjensen@gmail.com

All authors declare no conflicts of interests 


\section{Abstract}

Testicular microcalcifications consist of hydroxyapatite and their demonstration by ultrasound has been associated with increased risk of testicular germ cell cancer (TGCT). Here, we show that fibroblast growth factor 23 (FGF23), a bone-specific regulator of phosphate homeostasis, is expressed in testicular germ cell neoplasia in situ (GCNIS), embryonal carcinoma (EC), and human embryonic stem cells. FGF23 is not glycosylated in TGCTs and thus rapidly cleaved into a C-terminal fragment that serves as a competitive antagonist for full-length FGF23. High levels of C-terminal FGF23 occupy the receptor formed by Klotho and FGF receptor 1 (FGFR1) in the germ cells facilitating a shift in the expression of phosphate transport proteins from SLC34A2 to SLC34A1 in seminiferous tubules adjacent to GCNIS. Fgf23 knockout mice have a marked epididymal deposition of hydroxyapatite, while the testicular phenotype is milder with spermatogenic arrest and focal germ-cell-specific expression of the bone-like markers runt-related transcription factor 2 (RUNX2) and bone gammacarboxyglutamic acid-containing protein (BGLAP). In accordance, mice with no functional androgen receptor and lack of circulating gonadotropins develop microcalcifications in 94\% of cases and have lower S/c34a2, and higher S/c34a1 and Bglap expression. In accordance, human testicular specimens with microcalcifications also have lower SLC34A2, and focally germ cells express SLC34A1, BGLAP, and RUNX2. Importantly, calcium or phosphate induced osteogenic transdifferentiation of a spermatogonial cell line in vitro demonstrated by induction of alkaline phosphatase activity and deposition of hydroxyapatite, which could be fully rescued by pyrophosphate (PPi). Severe microcalcifications were also found in a mouse model with Sertoli-cell ablation particularly when Sertoli-ablation was conducted prepubertally where the germ cells retain stem cell potential. In conclusion, cancer-related microcalcifications may arise secondary to gonadal mineral alterations, which in combination with impaired Sertoli cell function and reduced PPi due to high alkaline phosphatase activity in GCNIS and TGCTs, facilitates osteogenic transdifferentiation of testicular germ cells and deposition of hydroxyapatite. 


\section{Introduction}

Extra-skeletal mineralization is often caused by an imbalance in inorganic phosphate and calcium homeostasis or availability of promoters or inhibitors of biomineralization ${ }^{1-3}$. Ultrasonic microlithiasis has been linked in several studies with an increased risk of testicular germ cell tumors (TGCTs) ${ }^{4-9}$ and may be an indication for a testicular biopsy or followup ultrasound if other risk factors are present. Microcalcifications are also a frequent histological finding in the testis of men with severely impaired fertility ${ }^{8,10}$ but ultrasonic microlithiasis is not always reflected by histological calcifications. The etiology of testicular microcalcifications is largely unknown, but they consist of hydroxyapatite normally found exclusively in the skeleton ${ }^{5,11-13}$. How hydroxyapatite is formed in the gonads remains unanswered as it normally requires cells with osteoblast-like characteristics ${ }^{14,15}$. Several factors are important for mineralization. Small integrin-binding ligand $\mathrm{N}$-linked glycoproteins (SIBLINGs) such as osteopontin (OPN) and dentin matrix acidic phosphoprotein 1 (DMP1) work to regulate mineralization in concert with bone-specific factors such as osteocalcin (BGLAP), runt-related transcription factor 2 (RUNX2), pyrophosphate (PPi), and alkaline phosphatase. However, accumulating evidence suggests that fibroblast growth factor 23 (FGF23) and its receptor Klotho, the phosphate transport proteins solute carrier family 34 A-1 and -3 (SLC34A-1 and -3), and vitamin D metabolizing enzymes are essential to maintain stable mineral homeostasis and changes in these factors may lead to extra-skeletal calcifications ${ }^{16-20}$. Interestingly, secondary hyperphosphatemia caused by lossof-function mutations in GaINAc-T3 and hence a lack of degradation-protective glycosylation of FGF23 leads to severe testicular microcalcifications ${ }^{21-23}$. Also a loss-of-function mutation in the main testicular phosphate transporter SLC34A2 led to severe testicular microcalcifications ${ }^{24}$. These studies indicate that both systemic and local changes in phosphate homeostasis may induce testicular microcalcifications. Therefore, we hypothesized that testicular microcalcifications caused by TGCTs may be due to the malignant cells producing factors leading to disturbances of intratesticular mineral homeostasis.

TGCTs are thought to originate from a common progenitor germ cell neoplasia in situ (GCNIS), which is characterized by the expression of pluripotency factors such as OCT4, NANOG, and high activity of placental alkaline phosphatase (PLAP) ${ }^{25-}$ 28. GCNIS undergoes malignant transformation and forms either a seminoma that retains germ cell characteristics or a non-seminoma that may contain components of embryonal carcinoma (EC) resembling human embryonic stem cells (hESCs), differentiated teratoma, yolk sac tumor, or choriocarcinoma ${ }^{29}$. During the malignant transformation of GCNIS into invasive TGCTs duplication of chromosome $12 p$ (often as isochromosome $12 p$ ) is the most consistent chromosomal aberration, and some of the genes located here are suggested to be involved in the dedifferentiation from GCNIS to $\mathrm{TGCT}^{29}$. FGF23 is usually produced exclusively in osteocytes, but the location of the gene on chromosome 12p may be crucial for its role in TGCT. FGF23 increases phosphate excretion by decreasing the luminal expression of SLC34A1 in the kidney and lowering the concentration of activate vitamin D by increasing the inactivating CYP24A1 enzyme and decreasing the activating CYP27B1 enzyme ${ }^{30}$. 
We have previously shown that local metabolism of vitamin D disappears during the malignant transformation of GCNIS to EC and that FGF23 is expressed in an EC-derived cell line ${ }^{31}$. O-glycosylation by GalNAc-T3 protects FGF23 from rapid degradation, while full-length FGF23 activates a receptor complex consisting of Klotho heterodimerization with FGF receptor 1 (FGFR1). However, FGF23 is capable of inducing Klotho-independent effects, and the cleaved C-terminal fragment (CFGF23) can bind and serve as a competitive antagonist for intact FGF23 (iFGF23) 32. Inactivating mutations in FGF23, GaINAC-T3, or Klotho lead to tumoral calcinosis partly through osteogenic transdifferentiation of mesenchymal derived cells due to altered mineral homeostasis and vitamin $\mathrm{D}$ metabolism, which also could be relevant etiological factors for testicular calcifications ${ }^{33}$. Here, we investigated whether TGCTs produce FGF23 that may alter testicular mineral homeostasis and thereby facilitate osteogenic transdifferentiation with deposition of hydroxyapatite. To address this question, we investigated the expression of mineral regulators and bone factors in human TGCT-associated calcifications, Fgf23 knockout $\left(F g f 23^{-/}\right)$mice, hypogonadal androgen-insensitive mice with microcalcifications, mice with microcalcifications due to Sertoli cell ablation, TGCT-derived cell line xenograft-bearing mice, and mineral deposition in a spermatogonial cell line (GC1) in vitro. 


\section{Results}

\section{FGF23 production in human testicular germ cell tumors and embryonic stem cells}

The mRNA expression of FGF23 was investigated in human testicular specimens containing normal testis, Sertoli-cell-only pattern, GCNIS, seminoma, and EC with or without components of teratoma. FGF23 mRNA was more highly expressed in EC components compared with normal testis and was positively associated with the expression of the pluripotency factors NANOG and OCT4 ( $\mathrm{R}=0.66, \mathrm{P}=0.049$, and $\mathrm{R}=0.61, \mathrm{P}=0.068$, respectively) (Fig. 1A-B). Two EC specimens with polyembryoma components had very high levels of FGF23. A higher expression of FGF23 in GCNIS than in normal testis was also confirmed in microdissected GCNIS cells (Fig. 1C). Moreover, microdissected fetal gonocytes and human embryonic stem cells (hESCs) also expressed FGF23 (Fig. 1C), but IHC showed very few gonocytes with detectable FGF23 expression (not shown). Instead, the high expression of FGF23 in hESC and EC was validated by a $~ 30$-fold higher expression of FGF23 in different strains of hESC cells and the EC-derived cell line NTera2 compared with normal testis (Fig. 1D). In contrast, the receptor Klotho $(K L)$ was highly expressed in normal testis and much lower expressed in GCNIS and hESC (Fig. 1C). IHC confirmed the marked expression of FGF23 solely in OCT4-positive GCNIS that also expressed FGFR1, while Klotho was exclusively expressed in normal germ cells and not in the OCT4-positive cancer cells. The differences at the transcriptional level indicate that FGF23 is expressed in the EC cells characterized by concomitant OCT4 expression but is virtually absent in seminoma despite marked OCT4 expression. Klotho was not expressed in EC or seminoma (Fig. 1E and Suppl. Table 1). Western blot confirmed the presence of two bands corresponding to the sizes of cFGF23 and iFGF23 in GCNIS and EC. NTera2 cells also expressed cFGF23, but FGF23 was not detected in normal testis or the seminoma-derived cell line TCam2 (Fig. 1F). cFGF23 and iFGF23 were expressed in an anaplastic seminoma, which is considered an intermediate between seminoma and EC due to the high proliferative index and morphological resemblance with EC (Fig. 1F and Suppl. Table 1). Production of FGF23 in GCNIS and EC cells was supported by measuring the total FGF23 (iFGF23 + cFGF23) and cFGF23 concentrations in seminal fluid from healthy men and TGCT patients. Healthy men had no detectable iFGF23 in the seminal fluid, and very few men had detectable cFGF23. A few men with GCNIS or EC had detectable levels of iFGF23 in the seminal fluid. In contrast, total FGF23 concentrations were significantly higher in men with EC compared with healthy men (Fig. $1 G)$.

\section{Renal and testicular vitamin D and phosphate homeostasis in NTera2 xenograft mice}

IHC staining of the NTera2 xenograft tumors on the flank of nude mice showed that FGF23 was expressed in relatively few (5-10\%) tumor cells, likely due to the partial somatic differentiation of the tumors, illustrated by only focal expression of OCT4 (Fig. 2A). This may explain the relatively low serum concentrations of human iFGF23 in nude mice with tumors, which were only 4-fold higher compared with control nude mice (Fig. 2B). Noteworthy, only NTera2 cells grown in vitro had detectable cFGF23 (Fig. 1F), which indicates that NTera2 cells in vivo may undergo somatic differentiation in response to host stimuli and turn on GalNAc-T3, which glycosylates iFGF23 to prevent rapid cleavage. NTera2 tumor-bearing mice had significantly higher Cyp27b1 and Cyp24a1 expression in both kidney and testis, whereas S/c34a1 and Bglap were 
significantly higher only in testis compared with nude mice without tumors (Fig. 2C). Expression of the phosphate transporter S/c34a1 was strongly positively correlated with the tumor size in both kidney and testis $(\mathrm{R}=0.63, \mathrm{P}=0.003$ and $\mathrm{R}=0.53, \mathrm{P}=0.012$, respectively) (Fig. 2D).

\section{Mineralization in reproductive organs of $\mathrm{Fgf23} \%$ mice}

Fgf23\%- mice had elevated serum concentrations of both calcium and phosphate compared with wildtype (WT) mice (Fig. $3 \mathrm{~A})$ and smaller testis, and spermatogenic arrest at the spermatocyte stage although a few tubules with complete spermatogenesis were found focally (not shown). Testicular evaluation showed no deposition of hydroxyapatite, but DMP1, OPN, and BGLAP were expressed in the cytoplasm of some germ cells in 0-15\% of the tubules in Fgf $23^{\%}$ mice and more rarely in WT mice (Fig. 3B-C). The phenotype was more severe with marked mineralization in cauda epididymis in some of the Fgf $23^{-/}$mice and none of the WT mice. DMP1, OPN, and BGLAP were highly expressed in the epididymis of Fgf23 ${ }^{-/}$mice, particularly in the lumen (Fig. 3D-E). DMP1 and BGLAP were not detected in the epididymal lumen of WT, whereas OPN was expressed in both WT and $\mathrm{Fgf23} \%$ mice, although more extensively in $\mathrm{Fgf2} \%$ mice.

\section{Testicular microcalcifications in hypogonadal and androgen receptor null or Sertoli cell-ablated mice}

Testicular microcalcifications are found in $\sim 30 \%$ of hypogonadal $(h p g)$ mice that lack circulating gonadotropins. This increased to $\sim 94 \%$ with concomitant global loss of the androgen receptor $(A R)$ (hpg.ARKO) ${ }^{34}$ (schematically illustrated in Fig. 4A). Sertoli cell-specific ablation of $A R$ in $h p g$ mice ( $h p g$.SCARKO) had no augmented effect on microcalcifications in the hpg mice, which indicates a role of the AR in other interstitial cells or AR-expressing cells outside the testis for the formation of microcalcifications. Interestingly, a shift in expression of phosphate transporters was observed in the testis of $h p g, h p g . S C A R K O$, and $h p g$.ARKO mice. The mice had higher expression of S/c34a1 and lower expression of S/c20a1 and S/c34a2 compared with WT mice. There were no significant differences in S/c20a1, S/c34a1, and S/c34a2 expression between hpg, hpg.SCARKO, or hpg.ARKO mice, despite the higher proportion of mice with microcalcifications in the hpg.ARKO group. However, Bglap was detected in testis from all hpg.ARKO and most hpg.SCARKO mice, which suggests that Bglap is expressed in mice with disturbance of Sertoli cell maturation and is more expressed in mice with the most microcalcifications (Fig. 4B). Ablation of Sertoli cells at postnatal day 18 induced substantial microcalcifications in mice shown by von Kossa and Alizarin Red staining (Fig. 4C). The microcalcifications persisted also when assessed in mice 1 year of age. The timing of ablation seemed to be important because Sertoli cell-ablation in adulthood (after puberty) caused no microcalcifications when determined after 90 days but was found 1 year after. Prepubertal ablation caused microcalcifications at all investigated time points (data not shown). Formation of microcalcifications depended on the presence of germ cells with stem cell potential since the ablation of Sertoli cells during embryonic development did not cause testicular microcalcifications either due to lack of maintenance or presence of germ cells in the gonads (data not shown). 


\section{Microcalcifications and expression of bone markers in human testis with malignant germ cells}

Ultrasonic testicular microlithiasis is often adjacent to TGCTs but can also be found in testis without TGCT or GCNIS (Fig. 5A). Testicular microlithiasis is not always associated with histological microcalcifications but von Kossa or Alizarin Red staining can confirm that the histological microcalcifications consist of hydroxyapatite (Fig. 5A). SLC34A1 (gene encoding NPT2A) is not expressed in normal testis but was present in some of the specimens containing both GCNIS and normal testis. In contrast, the phosphate transporter SLC34A2 (the gene encoding NPT2B) was abundantly expressed in the germ cells from normal testis and showed lower expression in specimens containing GCNIS (Fig. 5B). NPT2A and FGF23 were frequently found in GCNIS adjacent to microcalcifications. In contrast, Klotho was found in the germ cells in normal tubules, with or without adjacent microcalcifications, but not in GCNIS (Fig. 5C). The degrees of microcalcifications were divided into mild, moderate, or severe with actual bone formation in the most severe case (Fig. 5D-E). The milder degrees comprised focal luminal deposition of hydroxyapatite, while in the moderately affected specimen calcifications occupied most of the intraluminal area. Of note, BGLAP and alkaline phosphatase are late osteogenic markers, while RUNX2 is an early marker. We found no RUNX2 expression in cells from normal testis, but occasionally, when microcalcifications or bone formation were detected, a small fraction of the germ cells had cytoplasmic staining of RUNX2 supporting a bonelike phenotype of some germ cells (Fig. 5E and Suppl. Fig. 1). BGLAP was detected in germ cells adjacent to testicular microcalcifications and the core of the microcalcifications (Fig. 5C and Suppl. Fig. 1) but also in the GCNIS cells (Fig. 5B-C).

\section{Effects of calcium, phosphate, and pyrophosphate on mineralization of a spermatogonial cell line}

Alkaline phosphatase activity is present in most cells in the body and degrades the potent inhibitor of mineralization PPi. Alkaline phosphatase activity is markedly higher in GCNIS tubules compared with normal seminiferous tubules as determined by NBT/BCIP staining (Fig. 6A) due to a high expression of PLAP. PLAP is physiologically expressed only in immature germ cells (gonocytes) and is clinically used as a specific marker for GCNIS and seminoma. To determine if mineralization can be induced in the germ cells the mouse spermatogonial cell line GC1 was treated with increasing concentrations of calcium and phosphate, and mineral deposition was visualized by Alizarin Red. Mineralization was already seen after co-treatment with calcium and phosphate for two days, but also after seven days of treatment with calcium or phosphate alone (Fig. 6B). With a normal phosphate concentration ( $0.9 \mathrm{mM}), 3 \mathrm{mM}$ calcium was required to obtain a rapid mineralization after two days, whereas even $4 \mathrm{mM}$ phosphate induced no hydroxyapatite formation in a normal calcium concentration $(1.8 \mathrm{mM})$ after two or four days. However, just a mild increment in calcium to $2.0 \mathrm{mM}$ enabled five of the six used phosphate doses to induce rapid mineralization of the GC1 cells. Longer exposure (four and seven days) augmented the response in a dose-dependent manner. The addition of PPi, an inhibitor of mineralization, reduced mineralization significantly, whereas co-treatment with PPi and pyrophosphatase (PPA1) reintroduced mineralization (Fig. 6C). To assess the regulation of phosphatase activity in germ cells, a human cell line TCam2 was used as a positive control. TCam2 is derived from a seminoma and retains high expression of PLAP, as assessed by NBT/BCIP staining, which was critically dependent on an alkaline environment with marked phosphatase activity at pH 9, but not at 
bioRxiv preprint doi: https://doi.org/10.1101/2020.06.25.171355; this version posted June 27, 2020. The copyright holder for this preprint (which was not certified by peer review) is the author/funder. All rights reserved. No reuse allowed without permission.

pH 7 (Fig. 6D). Vehicle treated GC1 cells had virtually no alkaline phosphatase activity, but treatment with calcium and phosphate for four days increased alkaline phosphatase activity, which is known to be a late marker of osteogenic differentiation (Fig. 6C and data not shown). 


\section{Discussion}

This translational study shows that both benign and malignant associated testicular microcalcifications occur secondary to changes in gonadal phosphate and PPi homeostasis that facilitate an osteogenic transdifferentiation of testicular germ cells and deposition of hydroxyapatite. Microcalcifications are more prevalent in testicular biopsies with GCNIS (39\%) compared with biopsies without the presence of GCNIS $(2 \%)^{13}$. This marked difference may be explained by ectopic FGF23 production in the malignant cells causing disturbances of phosphate/calcium transport and vitamin D metabolism. In combination with increased alkaline phosphatase activity (PLAP expression) that degrades the endogenous inhibitor of mineralization PPi. FGF23 mRNA is highly expressed in some GCNIS/EC cells and hESC strains, but virtually undetectable in fetal gonocytes or classical seminoma cells. This implies that production of FGF23 depends on the the transformation from GCNIS to an invasive and highly pluripotent EC. FGF23 is located on chromosome 12p, which is duplicated in many hESC lines and virtually $100 \%$ of TGCTs including seminoma tumor components that do not express FGF23, which excludes chromosome $12 \mathrm{p}$ amplification as the main reason for FGF23 production. Instead, the marked expression in hESCs and EC highlights that FGF23 is an early embryonic signal. This suggestion is supported by the strong correlation between FGF23 and pluripotency factors OCT4 and NANOG, high FGF23 expression in EC with polyembryoma formation, and previous reports identifying FGF23 transcripts in hESCs and during early embryonic life but not in murine ESC $^{35,36}$.

The lack of GaINacT3 in EC and GCNIS ${ }^{37}$ suggests that FGF23 is rapidly cleaved and antagonizes the effect of iFGF23 on the adjacent germ cells expressing the Klotho/FGFR1 receptor ${ }^{1}$. Tumors from the EC-derived cell line NTera2 xenograft mice were characterized by somatic differentiation illustrated by the loss of OCT4 and FGF23 expression except for 5-10\% of the cancer cells in vivo. The marked transcriptional changes in the kidney and testis alter vitamin D and mineral homeostasis and appears to be the result of tumor burden or other secreted factors from the tumor. Although ectopic FGF23 expression without glycosylation, in theory, could explain the findings because cFGF23 will lead to high activated vitamin $D$ and phosphate, and a phenotype resembling Fgf $23^{\%}$ mice ${ }^{32}$. Testicular levels of phosphate are 3 fold higher than in serum and the marked deposition of hydroxyapatite in the cauda epididymis in $\mathrm{Fgf23} \%$ mice shows that loss of intact FGF23 signalling causes deposition of hydroxyapatite. Still, the testicular phenotype was milder with focal expression of SIBLING and bone-specific proteins in some germ cells despite marked systemic and epididymal changes in calcium and phosphate ${ }^{38,39}$. The local testicular mineral levels depend merely on specific transporters and sensors of calcium and phosphate in the reproductive organs. Gonadal phosphate homeostasis is a key determinant for microcalcification as patients with loss-of-function mutations in the predominant gonadal phosphate transporter SLC34A2 present exclusively with alveolar and testicular microcalcifications ${ }^{21,24}$. Moreover, patients with loss-of-function mutations in GalNAc-T3 and early degradation of intact to c-terminal FGF23 present with global calcifications and severe testicular microlithiasis and microcalcifications ${ }^{21}$, which also are frequent findings in patients with McCune-Albright syndrome and hypophosphatemia due to aberaant FGF23 handling ${ }^{40,41}$. FGF23 and Klotho are potent regulators of vitamin D and mineral homeostasis and strongly related to calcifications in multiple other tissues like the vasculature ${ }^{42}$. Now, we extend the list 
of tissues by showing massive deposition of hydroxyapatite in the epididymis of $F g f 23^{-/}$mice where the luminal phosphate concentration changes drastically ${ }^{38,39}$.

The high testicular mRNA expression of Cyp27b1, Cyp24a1, and S/c34a1 in NTera2 xenografted mice is in line with the higher expression of CYP27B1, CYP24A1, and BGLAP in Fgf23\%- mice and highlights that benign conditions also can disrupt testicular mineral homeostasis. Fgf23\% mice also have hypogonadism ${ }^{43}$ and spermatogenic arrest, which resemble the phenotype of some men with testicular dysgenesis syndrome characterized by incomplete spermatogenesis and low sex steroids that occasionally have testicular microcalcifications despite of no malignancy ${ }^{5,44}$. Microcalcifications in the benign testis could be caused by impaired Sertoli cell function due to low androgens/gonadotropin signaling leading to less definitive signals to the germ cells that may retain their prepubertal stem cell characteristics and therefore be susceptible to other differentiating signals such as the 3 -fold higher phosphate concentration ${ }^{34,45,46}$. Microcalcifications in almost all $h p g$ mouse with concomitant global $A R$ deletion support this suggestion as these mice have immature Sertoli cells and no spermatogenesis. Moreover, these mice had altered testicular phosphate homeostasis characterized by a tendency towards lower S/c34a2 and higher S/c34a1 expression compared with WT mice in accordance with the malignant-induced changes in phosphate transporters associated with microcalcifications. However, hpg mice and hpg mice with Sertoli specific $A R$ deletion had similar changes in phosphate transporters and only 30-36\% frequency of microlithiasis, which suggests that other mechanisms like peritubular-Sertoli cell interaction may be involved. The bone marker Bglap was detected in all hpg mice with global $A R$ deletion but not in hpg mice, indicating that some testicular cells undergo osteogenic transdifferentiation and this may drive or accompany the abundant deposition of hydroxyapatite. We have previously shown that activated vitamin D induces an osteogenic transdifferentiation of NTera2 cells that start to express bone-specific proteins such as BGLAP ${ }^{31}$. However, the observed osteogenic transdifferentiation in $h p g$ mice occurs in nonmalignant cells, and the question is which testicular cell is prone to undergo osteogenic transdifferentiation. Peritubular cells could in theory become bone-like because they are mesenchymal-derived and such fibroblast like cells undergo osteogenic transdifferentiation during vascular calcification and other sites of extra-skeletal mineralization ${ }^{42}$. Human Sertoli cells can form large-cell calcifying tumors ${ }^{47}$, which clearly show that other gonadal cell types have the potential to become bone-like. In mice, Sertoli cell-ablation prior to puberty caused always extensive intratubular microcalcifications ${ }^{48}$. Unlike, Sertoli cell-ablation in adulthood that caused no microcalcifications when assessed three months later despite a greater burden of immediate intratubular cell death, however, microcalcifications did develop after one year. This finding is important because it demonstrates that microcalcifications are not caused by massive intratubular cell death, at least not in mice. Instead, microcalcifications may be dependent on the survival of some germ cells with prepubertal stem cell characteristics suggesting that Sertoli cell maturation is essential for protection against osteogenic transdifferentiation of the germ cells.

RUNX2 is an essential transcription factor for osteoblast development and normal germ cells express a different isoform of RUNX2 $2^{49,50}$. In all mouse WT models in this study RUNX2 expression was not detected in germ cells. Instead, the mature 
bone marker BGLAP was expressed in a fraction of cells that morphologically resembled germ cells. Unfortunately, there was no cell-tracing marker in the mice models so the required tracing experiments to prove that these bone-like cells originated from the germ cells could not be conducted. Instead, a spermatogonial mouse cell line was exposed to concentration of calcium and phosphate that frequently are found in intratesticularly or in the epididymis ${ }^{38}$. After 2-7 days of exposure the spermatogonia started to deposit hydroxyapatite characterized by Alizarin Red staining. The spermatogonial cells may not complete a definitive osteogenic transdifferentiation but they become more bone-like illustrated by their ability to mineralize. One of the most potent inhibitors of mineralization is PPi, which can be degraded by alkaline phosphatase or pyrophosphatase ${ }^{51}$. PPi prevented the observed spermatogonial mineralization induced by calcium and phosphate, which was reintroduced in the presence of pyrophosphatase degrading PPi. This highlights a fundamental role for PPi as an inhibitor of spermatogonial mineralization. PLAP, which can convert PPi to Pi like other alkaline phosphatases, is physiologically expressed by primordial and malignant germ cells ${ }^{28,52}$. Alkaline phosphatase is absolutely required for normal bone formation and regulates vascular matrix mineralization by inactivation of the mineralization inhibitors PPi and OPN ${ }^{53,54}$. We show here TCam2 cells, which have a high expression of PLAP, can inhibit $\mathrm{PPi}$ in alkaline $\mathrm{pH}$, suggesting that mineralization is promoted by malignant cells. This implies that men with GCNIS and TGCTs are prone to microcalcifications due to lower PPi levels caused by increased alkaline phosphatase activity ${ }^{53}$. Several other inhibitors and promoters of mineralization could also be involved, but the marked epididymal mineralization

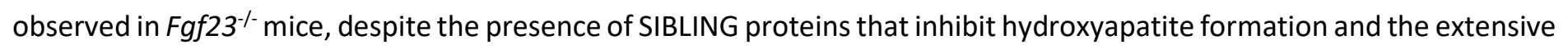
testicular microcalcifications in men with mutation in SLC34A2 $2^{24}$, suggest that a change of just one component is enough to form microcalcifications. Bone formation is commonly observed in teratomas but can occur without malignancy. Mature bone tissue formation has been reported in the testis after trauma or bleeding without signs of GCNIS or invasive $\mathrm{TGCTs}^{55}$. Here, we also present mature intratesticular bone with Howship's lacunae despite of no detection of GCNIS or malignant cells. A comprehensive analysis of germ cells adjacent to the bone tissue revealed a few RUNX2 positive germ cells but none of them expressed any of the other investigated bone markers or deposition of hydroxyapatite, which indicates that the mature bone may have been formed in the interstitial compartment through a different mechanism related to the trauma rather than alterations in mineral homeostasis leading to testicular microcalcifications.

In conclusion, we show that the formation of microcalcifications in the testis can occur in men with TGCTs or more rare disorders associated with Sertoli cell dysfunction or androgen insufficiency, which all lead to local changes in phosphate, calcium, and PPi homeostasis. These changes alone or in combination can drive osteogenic transdifferentiation of testicular cells particularly germ cells resulting in intratubular deposition of hydroxyapatite. 


\section{Materials and Methods}

\section{Human tissue samples}

Patients were recruited from the Department of Growth and Reproduction, Rigshospitalet, Denmark in accordance with the Helsinki Declaration after approval from the local ethics committee (Permit No. H-15000931, H-17004362, KF $012006-$ 3472). Adult testis samples were obtained from orchiectomy specimens performed due to TGCT. The tissue surrounding the tumor contained tubules with either GCNIS cells or normal/impaired spermatogenesis. Each sample was divided into fragments, which were either snap-frozen and stored at $-80^{\circ} \mathrm{C}$ for RNA extraction or fixed overnight at $4^{\circ} \mathrm{C}$ in formalin or paraformaldehyde and subsequently embedded in paraffin. An experienced pathologist evaluated all samples and IHC markers were used for TGCT to ensure the histologic subtypes of the tumor. Fetal gonads were collected after elective terminations for non-medical reasons and gestational age was estimated by ultrasound at the Department of Gynecology (Rigshospitalet/Hvidovre Hospital, Denmark) after approval by the local ethics committee (H-1-2012-007).

\section{Microarray}

For this study the data were extracted from microarray analysis, which was performed and published in full previously ${ }^{56}$. Briefly snap-frozen tissues were fixed in 75\% ethanol and analyzed for AP-2 $\gamma$ (sc-12762, Santa Cruz) by IHC to identify gonocytes, oogonia, and GCNIS and a slide was stained for alkaline phosphatase activity detectable in GCNIS and fetal germ cells. Before microdissection, slides were stained with nitroblue tetrazolium (NBT)-5-bromo-4-chloro-3-indolyl phosphate (BCIP). RNA was purified using Ambion RNAqueous micro kit (Applied Biosystem/Ambion). The quality of RNA was evaluated using Bioanalyzer Picokit (Agilent Technologies). Samples were amplified in two rounds using the MessageAMP ${ }^{\text {TM }}$ II, an RNA amplification Kit (Applied Biosystem/Ambion). RNA was reverse transcribed using $50 \mathrm{ng} / \mu \mathrm{L}$ random hexamer primers. Analyses were conducted on three hESC, microdissected fetal oogonia, microdissected fetal gonocyte, microdissected GCNIS, tissue containing different fractions of GCNIS and normal testis, and normal testis samples. Agilent Whole Human Genome Microarray 4x44K chips, Design Number 014850 (Agilent Technologies) were used for arrays. Hybridization and scanning of one-color arrays were performed as described by the manufacturer and analyzed using Agilent Feature extraction software (version 9.1.3.1).

\section{Quantitative RT-PCR (qRT- PCR)}

RNA was extracted from 13 tissue specimens with classical seminoma, 10 ECs which some included components of teratoma, and 30 GCNIS samples (GCNIS adjacent to EC, seminoma, mixed tumor, and six GCNIS samples without an overt tumor). RNA from normal testis was purified from three orchiectomy specimens with seminiferous tubules with varying degrees of full and partial spermatogenesis but with no GCNIS or tumor. Two normal testis RNA samples were purchased from two different companies (Applied Biosystems/Ambion and Clontech). RNA and cDNA preparation and qRT-PCR were conducted as described previously ${ }^{57}$. qRT-PCR was performed using primers listed in Suppl. Table 3. The representative 
bands from each primer combination were sequenced for verification (Eurofins MWG GmbH). qRT-PCR analyses were performed twice in duplicates on two different plates using a Stratagene Mx300P cycler with SYBR Green QPCR Master Mix (Stratagene). Changes in gene expression were determined with the comparative CT method using 82-microglobulin $(82 M)$ as a control gene in both human and mouse tissues.

\section{Western blot}

Frozen tissues prepared for western blot included adult normal testis, testis with GCNIS, homogeneous anaplastic seminoma, EC samples, and cell lysates from NTera2 and TCam2 cells. The tissues were homogenized in RIPA lysis buffer with protease inhibitor cocktail set III (Calbiochem). After centrifugation, supernatants were collected and diluted in SDS Sample buffer and heated for $5 \mathrm{~min}$ at $95^{\circ} \mathrm{C}$. Proteins were separated on an 8-16\% gradient gel (Pierce) and transferred to a PVDF membrane (Biorad). The membrane was blocked in 5\% milk for $1 \mathrm{~h}$ and incubated overnight with primary antibody (diluted 1:200, \#sc-16849). ß-actin was used as loading control (diluted 1:200, \#sc-47778). The membranes were further incubated for $1 \mathrm{~h}$ with an HRP-conjugated secondary antibody. Membranes were washed in TBST and protein signal was detected using 1-step NBT/BCIP (Pierce).

\section{Immunohistochemistry}

IHC staining was performed as described previously ${ }^{58}$. Briefly, antigen retrieval was conducted by microwaving for 15 min in TEG buffer before incubation with 2\% non-immune goat serum (Zymed Histostain kit) or $0.5 \%$ milk powder diluted in TBS. Subsequently, slides were incubated with primary antibodies overnight at $4^{\circ} \mathrm{C}$ (Suppl. Table 2 ) followed by secondary antibody and a peroxidase-conjugated streptavidin complex (Zymed Histostain kit) was used as a tertiary layer. Visualization was performed with amino ethyl carbazole. Between incubation steps the slides were washed with TBS. Counterstaining was performed with Meyer hematoxylin. All experiments were performed with control staining without primary antibody. Staining was classified according to an arbitrary semiquantitative reference scale depending on the intensity of staining and the proportion of cells stained: +++, strong staining in nearly all cells; ++, moderate staining in the majority of the cells; +, weak staining or a low percentage of cells stained; +/-, very weak staining in single cells; none, no positive cells detected.

\section{NTera2 xenografts and treatments}

All animal experiments were performed in compliance with the Danish Animal Experiments Inspectorate (license number 2011/561-1956) and conducted as previously described ${ }^{31}$. Mice were housed and interventions were conducted at Pipeline Biotech in a pathogen-free area. NTera2 cells were grown under standard conditions in $175 \mathrm{~cm}^{2}$ flasks and media were changed every 48 hours. Matrigel (BD Biosciences) was diluted in Dulbecco's modified Eagle's medium (DMEM)

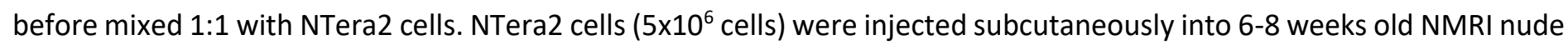
mice (Fox $1^{\text {nu }}$, Taconic Europe) in the flanks of male nude mice. The NTera2 cells were grown on the mice for 28-56 days. Tumor volumes were calculated from two tumor diameter measurements using a Vernier caliper: tumor volume $=\mathrm{L} \times \mathrm{W}$ $\mathrm{x} 1 / 2 \mathrm{~W}$. If a tumor diameter of $12 \mathrm{~mm}$ was reached the animals were sacrificed. At the end of the study, mice were 
euthanized according to the animal welfare euthanasia statement. Tumors, kidney, and testis were harvested and weighed, and half was fixed in formalin and embedded in paraffin for IHC and the other half was snap-frozen.

\section{Hypogonadal mice with androgen receptor ablation globally or specifically in the Sertoli cells and Sertoli cell-ablated} mice

Mice were bred in Glasgow and all procedures carried out under UK Home Office License and with the approval of a local ethical review committee. $h p g$.SCARKO and $h p g$.ARKO mice were generated as previously described ${ }^{34,59}$. SCARKO and ARKO mice were generated by crossing mice carrying floxed $\operatorname{Ar}\left(A r^{f l}\right)$ with mice expressing Cre regulated by the Sertoli specific promoter of AMH (Amh-Cre) or the ubiquitous promoter PGK-1. hpg.SCARKO mice were generated by crossing female $A r^{\mathrm{fl} / f \mathrm{f}}$ mice heterozygous for the $\mathrm{GnRH}$ deletion ( $\left.h p g /+\right)(\mathrm{C} 3 \mathrm{HE} / \mathrm{HeH}-101 / \mathrm{H})$ with male $h p g /+$ mice expressing AmhCre. The $h p g$.ARKO was generated the same way using a Pgk1-Cre instead of Amh-Cre. The mice were euthanized at 9-11 weeks of age by cervical dislocation. Sertoli cell ablated mice were generated as previously described ${ }^{48}$. Briefly, Amh;iDTR mice were injected subcutaneously with a single acute dose (100 ng in $50 \mu \mathrm{l}$ ) of DTX or with $50 \mu \mathrm{l}$ sterile water (vehicle) at postnatal day 18. The mice were euthanized at postnatal day 80.

\section{FGF23 measurements in serum and seminal plasma}

Human iFGF23 and total FGF23 (iFGF23 + cFGF23) were measured in duplicates in batched assays using assays from Immuntopics (Immutopics, \#60-6100, \#60-6600).

\section{In vitro cell cultures}

hESC lines were cultured in Sheffield as described previously ${ }^{60}$. $\mathrm{H7}$ cells with or without genomic aberrations were sorted using a fluorescence-activated cell sorter (FACS) and only cells expressing the pluripotency marker SSEA3 (undifferentiated cells) were analyzed. GC1 cells (ATCC ${ }^{\circledR}$ CRL-2053 ${ }^{\mathrm{TM}}$ ) were grown under standard conditions at $37^{\circ} \mathrm{C}$ at $5 \% \mathrm{CO}_{2}$ in $\mathrm{DMEM}$ supplemented with penicillin $(100 \mathrm{U} / \mathrm{ml})$ and streptomycin $(100 \mathrm{mg} / \mathrm{ml})$ (Gibco). To investigate calcification in the GC1 cells, the cells were grown in 24-well plates and treated with increasing concentrations of $\mathrm{CaCl}_{2}$ and $\mathrm{NaH}_{2} \mathrm{PO}_{4} \cdot \mathrm{Na}_{2} \mathrm{HPO}_{4}$ alone or in combination with PPi (Merck, \#P8010) and/or phosphatase (Prospec, \#ENZ-241). The medium was changed every second day.

\section{von Kossa, Alizarin Red, and BCIP/NBT staining}

For von Kossa staining of tissue sections, the paraffin sections were first deparaffinized and rinsed in $\mathrm{ddH}_{2} \mathrm{O}$. Sections were then incubated with $1 \%$ silver nitrate solution under ultraviolet light for $20 \mathrm{~min}$. Thereafter, the sections were rinsed in $\mathrm{ddH}_{2} \mathrm{O}$ and incubated with $5 \%$ sodium thiosulfate for $5 \mathrm{~min}$ and rinsed in $\mathrm{ddH}_{2} \mathrm{O}$ (and sometimes counterstained with Mayer's hematoxylin) and dehydrated through graded alcohol and clear in xylene. For Alizarin Red staining of tissue sections, deparaffinized sections were stained with $2 \%$ Alizarin Red solution ( $\mathrm{pH} 4.1-4.3$ ) for 5 minutes. The sections were then dehydrated in acetone and acetone-xylene (1:1) and cleared in xylene. For Alizarin Red staining of GC1 cells, the cells were washed in PBS and fixed in 10\% formalin for $10 \mathrm{~min}$. Thereafter, the cells were washed in $\mathrm{ddH}_{2} \mathrm{O}$ and incubated with 
0.5\% Alizarin Red ( $\mathrm{pH} 4.1-4.3$ ) for 20 min protected from light with light shaking. Cells were washed 2-3 times with dd $\mathrm{H}_{2} \mathrm{O}$ and left to dry. Cryosections $(10 \mu \mathrm{m})$ were treated with BCIP/NBT mixture for $90 \mathrm{sec}$. The BCIP/NBT mixture consisted of $45 \mu \mathrm{l}$ BCIP stock solution and $35 \mu \mathrm{l}$ NBT stock solutions in $10 \mathrm{ml}$ water. Stock solutions: $50 \mathrm{mg} / \mathrm{ml}$ 5-bromo-4-chloro-3indolyl phosphate (BCIP, Sigma B8503) in 100\% dimethylformamide (Sigma D4254) and $75 \mathrm{mg} / \mathrm{ml}$ nitroblue tetrazolium (NBT, Sigma N6876) in 70\% v/v dimethylformamide/distilled water. The reaction was stopped in water (1 min). BCIP/NBT staining of cell lines was performed the same way but in citrate buffer $(\mathrm{pH}=7)$ or relevation buffer $(\mathrm{pH}=9.2-9.5)$.

\section{Statistics}

Data were analyzed using GraphPad Prism v. 8 (GraphPad Software). Gaussian distribution of all numerical variables was evaluated by QQ-plots. Unpaired Student's t-test was used between two groups in mice. One-way ANOVA followed by Dunnett's multiple comparisons test was used to test for differences between gene expression in human normal testis and tumors, levels of iFGF23 and cFGF23 in seminal fluid from healthy men and tumor patients, and between WT and the different $h p g$ mice models. For correlation analyses residual plots were evaluated to secure the validity for the correlation analyses. As a result, linear regression analyses were used to investigate the link between FGF23 and the pluripotency genes OCT4 and NANOG in EC, and between tumor size and S/c34a1 expression in kidney and testis of xenografted mice. Statistical significance determined at the following levels: not significant (ns), $p>0.05, * p<0.05, * * p<0.01$, and $* * * p<0.001$, $* * * * p<0.0001$.

\section{Acknowledgements}

We thank Giulio Spagnoli for the MAGE antibody. We gratefully acknowledge several urologists and pathologists of the Greater Copenhagen area hospitals for their help with collecting the tissue samples. We thank Betina F. Nielsen, Bonnie Håkansson, Ana R. Nielsen, and Brian V. Hansen for skillful technical assistance. We appreciate the efforts by Carsten L. Buus and Klaus Kristensen from Pipeline Biotech, who performed the xenografting. We also thank all the patients and donors who took part in this study.

\section{Funding}

Danish Cancer Society, Forskningsrådet for sundhed og sygdom, Novo Nordisk Foundation, Aase og Ejnar Danielsens fond, Hørslev Fonden, Dagmar Wilhelms fond, and Ib Henriksens fond. 


\section{References}

1. Rowe, P. S. N. Regulation of Bone-Renal Mineral and Energy Metabolism: The PHEX, FGF23, DMP1, MEPE ASARM Pathway. Crit. Rev. Eukaryot. Gene Expr. 22, 61-86 (2012).

2. Martin, A. \& Quarles, L. D. Evidence for FGF23 Involvement in a Bone-Kidney Axis Regulating Bone Mineralization and Systemic Phosphate and Vitamin D Homeostasis. in Advances in Experimental Medicine and Biology (ed. Kuro-o, M.) vol. 728 65-83 (Springer US, 2012).

3. Shanahan, C. M., Crouthamel, M. H., Kapustin, A. \& Giachelli, C. M. Arterial Calcification in Chronic Kidney Disease: Key Roles for Calcium and Phosphate. Circ. Res. 109, 697-711 (2011).

4. Tan, I. B. et al. Testicular microlithiasis predicts concurrent testicular germ cell tumors and intratubular germ cell neoplasia of unclassified type in adults. Cancer 116, 4520-4532 (2010).

5. Pedersen, M. R., Rafaelsen, S. R., Møller, H., Vedsted, P. \& Osther, P. J. Testicular microlithiasis and testicular cancer: review of the literature. Int. Urol. Nephrol. 48, 1079-1086 (2016).

6. Pedersen, M. R. et al. Is testicular macrocalcification a risk for malignancy. J. Ultrasound Med. 37, 2949-2953 (2018).

7. Leblanc, L. et al. Testicular microlithiasis and testicular tumor: a review of the literature. Basic Clin. Androl. 28, 8 (2018).

8. Ganem, J. P., Workman, K. R. \& Shaban, S. F. Testicular microlithiasis is associated with testicular pathology. Urology 53, 209-213 (1999).

9. Venkataramappa, S., Chikkannaiah, P., Lalyanayak, P. \& Rao, S. Ossifying seminoma arising from cryptorchid testis masquerading as acute abdomen. J. Sci. Soc. 43, 51-53 (2016).

10. Mazzilli, F. et al. Seminal profile of subjects with testicular microlithiasis and testicular calcifications. Fertil. Steril. 84, 243-245 (2005).

11. De Jong, B. W. D. et al. Raman spectroscopic analysis identifies testicular microlithiasis as intratubular hydroxyapatite. J. Urol. 171, 92-96 (2004).

12. Smith, G. D., Steele, I., Barnes, R. B. \& Levine, L. A. Identification of seminiferous tubule aberrations and a low incidence of testicular microliths associated with the development of azoospermia. Fertil. Steril. 72, 467-471 (1999).

13. Kang, J., Rajpert-De Meyts, E., Giwercman, A. \& Skakkebæk, N. E. The association of testicular carcinoma 'in situ' with intratubular microcalcifications. J. Urol. Pathol. 2, 235-242 (1994).

14. Azpiazu, D., Gonzalo, S., González-Parra, E., Egido, J. \& Villa-Bellosta, R. Role of pyrophosphate in vascular calcification in chronic kidney disease. Nefrol. (English Ed. 38, 250-257 (2018).

15. Boström, K., Watson, K. E., Stanford, W. P. \& Demer, L. L. Atherosclerotic calcification: Relation to developmental osteogenesis. Am. J. Cardiol. 75, 88B-91B (1995).

16. Yuan, Q. et al. Increased Osteopontin Contributes to Inhibition of Bone Mineralization in FGF23-Deficient Mice. J. Bone Miner. Res. 29, 693-704 (2014).

17. Lieben, L. et al. Normocalcemia is maintained in mice under conditions of calcium malabsorption by vitamin Dinduced inhibition of bone mineralization. J. Clin. Invest. 122, 1803-1815 (2012).

18. Golub, E. E. Role of matrix vesicles in biomineralization. Biochim. Biophys. Acta - Gen. Subj. 1790, 1592-1598 
(2009).

19. Komori, T. et al. Targeted Disruption of Cbfa1 Results in a Complete Lack of Bone Formation owing to Maturational Arrest of Osteoblasts. Cell 89, 755-764 (1997).

20. Ducy, P. et al. Increased bone formation in osteocalcin-deficient mice. Nature 382, 448-452 (1996).

21. Garringer, H. J. et al. Two novel GALNT3 mutations in familial tumoral calcinosis. Am. J. Med. Genet. Part A 143A, 2390-2396 (2007).

22. Campagnoli, M. F. et al. Familial tumoral calcinosis and testicular microlithiasis associated with a new mutation of GALNT3 in a white family. J. Clin. Pathol. 59, 440-442 (2006).

23. Kato, K. et al. Polypeptide GalNAc-transferase T3 and Familial Tumoral Calcinosis. J. Biol. Chem. 281, 1837018377 (2006).

24. Corut, A. et al. Mutations in SLC34A2 cause pulmonary alveolar microlithiasis and are possibly associated with testicular microlithiasis. Am. J. Hum. Genet. 79, 650-656 (2006).

25. Skakkebaek, N. E. Possible carcinoma-in-situ of the testis. Lancet 516-517 (1972).

26. Rajpert-De Meyts, E. et al. Developmental expression of POU5F1 (OCT-3/4) in normal and dysgenetic human gonads. Hum. Reprod. 19, 1338-1344 (2004).

27. Hart, A. H. et al. The pluripotency homeobox gene NANOG is expressed in human germ cell tumors. Cancer 104, 2092-2098 (2005).

28. Jacobsen, G. K. \& Norgaard-Pedersen, B. Placental alkaline phosphatase in testicular germ cell tumours and in carcinoma-in-situ of the testis. Acta Pathol. Microbiol. Immunol. Scand. - Sect. A Pathol. 92, 323-329 (1984).

29. Rodriguez, S. et al. Expression profile of genes from $12 \mathrm{p}$ in testicular germ cell tumors of adolescents and adults associated with $\mathrm{i}(12 \mathrm{p})$ and amplification at 12p11.2-p12.1. Oncogene 22, 1880-1891 (2003).

30. Shimada, T. et al. FGF-23 Is a Potent Regulator of Vitamin D Metabolism and Phosphate Homeostasis. J. Bone Miner. Res. 19, 429-35 (2004).

31. Blomberg Jensen, M. et al. Vitamin D Metabolism and Effects on Pluripotency Genes and Cell Differentiation in Testicular Germ Cell Tumors In Vitro and In Vivo. Neoplasia 14, 952-963 (2012).

32. Goetz, R. et al. Isolated C-terminal tail of FGF23 alleviates hypophosphatemia by inhibiting FGF23-FGFR-Klotho complex formation. Proc. Natl. Acad. Sci. 107, 407-412 (2010).

33. Farrow, E. G., Imel, E. A. \& White, K. E. Hyperphosphatemic familial tumoral calcinosis (FGF23, GALNT3 and aKlotho). Best Pract. Res. Clin. Rheumatol. 25, 735-747 (2011).

34. O'Shaughnessy, P. J., Monteiro, A., Verhoeven, G., De Gendt, K. \& Abel, M. H. Occurrence of testicular microlithiasis in androgen insensitive hypogonadal mice. Reprod. Biol. Endocrinol. 7, 88 (2009).

35. Cormier, S., Leroy, C., Delezoide, A.-L. \& Silve, C. Expression of fibroblast growth factors 18 and 23 during human embryonic and fetal development. Gene Expr. Patterns 5, 569-573 (2005).

36. Wei, C. L. et al. Transcriptome Profiling of Human and Murine ESCs Identifies Divergent Paths Required to Maintain the Stem Cell State. Stem Cells 23, 166-185 (2005).

37. Rajpert-De Meyts, E. et al. Changes in the profile of simple mucin-type O-glycans and polypeptide GaINActransferases in human testis and testicular neoplasms are associated with germ cell maturation and tumour 
differentiation. Virchows Arch. 451, 805-814 (2007).

38. Jenkins, A. D., Lechene, C. P. \& Howards, S. S. Concentrations of seven elements in the intraluminal fluids of the rat seminiferous tubules, rete testis, and epididymis. Biol. Reprod. 23, 981-987 (1980).

39. Jenkins, A. D., Lechene, C. P. \& Howards, S. S. The Effect of Estrogen Administration In Vivo on the Elemental Composition of the Intraluminal Fluids of the Seminiferous tubules, Rete Testis, and Epididymis of the Rat. J. Androl. 4, 272-275 (1983).

40. Wasniewska, M. et al. Testicular microlithiasis: An unreported feature of McCune-Albright syndrome in males. J. Pediatr. 145, 670-672 (2004).

41. Kobayashi, K. et al. Expression of FGF23 is correlated with serum phosphate level in isolated fibrous dysplasia. Life Sci. 78, 2295-2301 (2006).

42. Memon, F. et al. Does Fgf23-klotho activity influence vascular and soft tissue calcification through regulating mineral ion metabolism? Kidney Int. 74, 566-570 (2008).

43. DeLuca, S. et al. Amelioration of the premature ageing-like features of Fgf-23 knockout mice by genetically restoring the systemic actions of FGF-23. J. Pathol. 216, 345-355 (2008).

44. Rebourcet, D. et al. Sertoli Cells Maintain Leydig Cell Number and Peritubular Myoid Cell Activity in the Adult Mouse Testis. PLoS One 9, e105687 (2014).

45. Sharpe, R. M., McKinnell, C., Kivlin, C. \& Fisher, J. S. Proliferation and functional maturation of Sertoli cells, and their relevance to disorders of testis function in adulthood. Reproduction 125, 769-784 (2003).

46. O’Shaughnessy, P. J., Verhoeven, G., De Gendt, K., Monteiro, A. \& Abel, M. H. Direct action through the sertoli cells is essential for androgen stimulation of spermatogenesis. Endocrinology 151, 2343-2348 (2010).

47. Gourgari, E., Saloustros, E. \& Stratakis, C. A. Large-cell calcifying Sertoli cell tumors of the testes in pediatrics. Curr. Opin. Pediatr. 24, 518-522 (2012).

48. Rebourcet, D. et al. Sertoli cells control peritubular myoid cell fate and support adult leydig cell development in the prepubertal testis. Dev. 141, 2139-2149 (2014).

49. Ogawa, S. et al. Cbfa1, an Essential Transcription Factor for Bone Formation, Is Expressed in Testis from the Same Promoter Used in Bone. DNA Res. 7, 181-185 (2000).

50. Jeong, J. et al. Expression of Runx2 transcription factor in non-skeletal tissues, sperm and brain. J. Cell. Physiol. 217, 511-517 (2008).

51. Orriss, I. R. Extracellular pyrophosphate: The body's "water softener". Bone 115243 (2020) doi:10.1016/j.bone.2020.115243.

52. Kiffer-Moreira, T. et al. Catalytic Signature of a Heat-Stable, Chimeric Human Alkaline Phosphatase with Therapeutic Potential. PLoS One 9, e89374 (2014).

53. Lomashvili, K. A., Cobbs, S., Hennigar, R. A., Hardcastle, K. I. \& O’Neill, W. C. Phosphate-Induced Vascular Calcification: Role of Pyrophosphate and Osteopontin. J. Am. Soc. Nephrol. 15, 1392-1401 (2004).

54. Jono, S., Peinado, C. \& Giachelli, C. M. Phosphorylation of Osteopontin Is Required for Inhibition of Vascular Smooth Muscle Cell Calcification. J. Biol. Chem. 275, 20197-20203 (2000).

55. Yoneda, F., Kagawa, S. \& Kurokawa, K. Dystrophic Calcifying Nodule with Osteoid Metaplasia of the Testis. Br. J. Urol. 51, 413 (1979). 
56. Sonne, S. B. et al. Analysis of Gene Expression Profiles of Microdissected Cell Populations Indicates that Testicular Carcinoma In situ Is an Arrested Gonocyte. Cancer Res. 69, 5241-5250 (2009).

57. Blomberg Jensen, M. et al. Expression of the vitamin D receptor, 25-hydroxylases, 1 $\alpha$-hydroxylase and 24hydroxylase in the human kidney and renal clear cell cancer. J. Steroid Biochem. Mol. Biol. 121, 376-382 (2010).

58. Blomberg Jensen, M. et al. Vitamin D receptor and vitamin D metabolizing enzymes are expressed in the human male reproductive tract. Hum. Reprod. 25, 1303-1311 (2010).

59. O'Shaughnessy, P. J., Monteiro, A., Verhoeven, G., De Gendt, K. \& Abel, M. H. Effect of FSH on testicular morphology and spermatogenesis in gonadotrophin-deficient hypogonadal mice lacking androgen receptors. Reproduction 139, 177-184 (2010).

60. Andrews, P. W., Goodfellow, P. N., Shevinsky, L. H., Bronson, D. L. \& Knowles, B. B. Cell-surface antigens of a clonal human embryonal carcinoma cell line: Morphological and antigenic differentiation in culture. Int. J. Cancer 29, 523-531 (1982). 


\section{Figure 1}
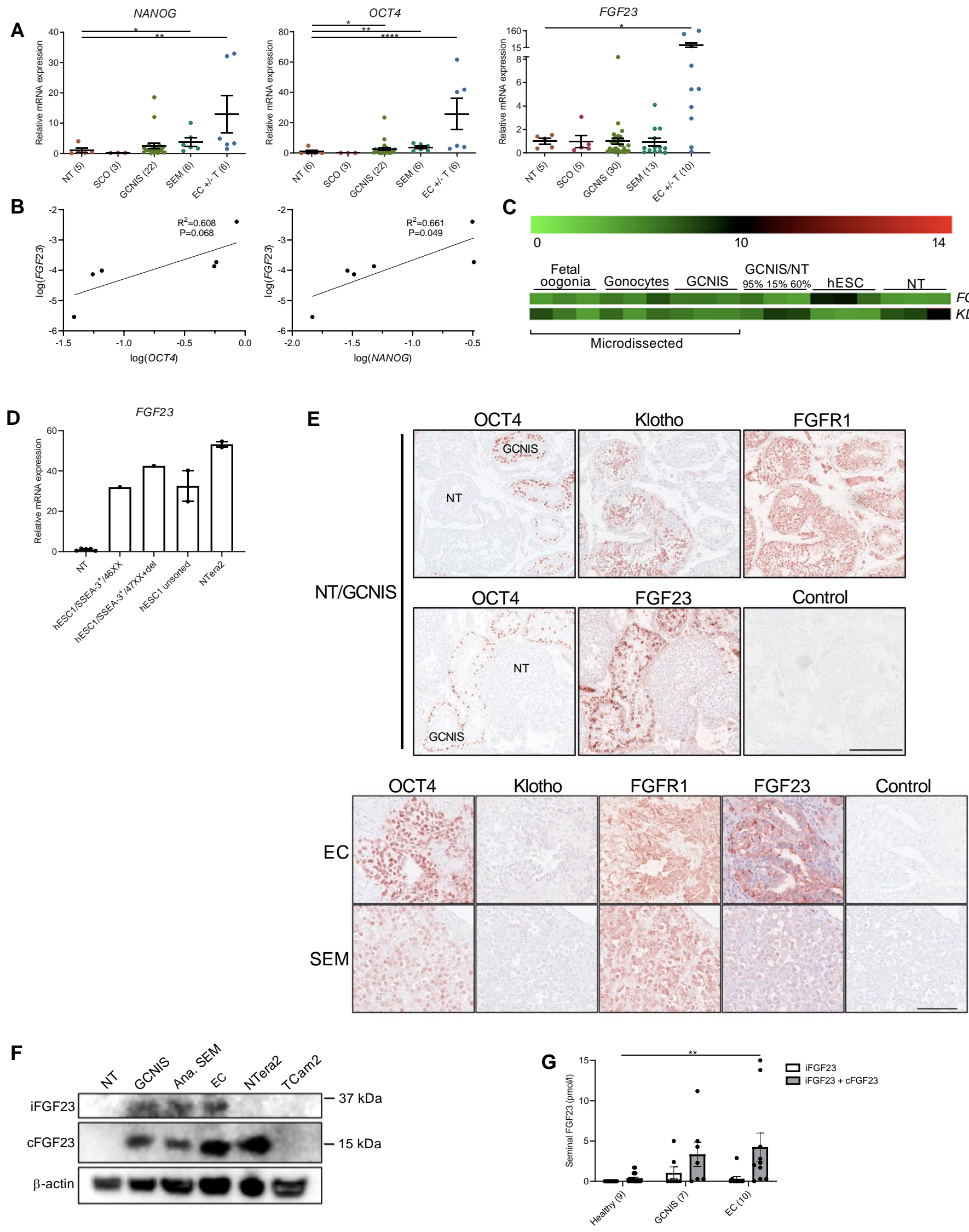
Ectopic expression of FGF23 in human testicular germ cell tumors and embryonic stem cells. (A) mRNA expression levels of the pluripotency factors NANOG and OCT4, and FGF23 in normal testis (NT), Sertoli-cell-only (SCO) pattern, GCNIS, seminoma (SEM), and EC +/- teratoma (T). (B) Correlations between gene expression of FGF23 and OCT4 or NANOG $(\mathrm{n}=6)$. (C) Microarray showing mRNA expression levels of FGF23 and $K L$ in microdissected fetal oogonia, gonocytes, GCNIS compared with tissues sample with varying fractions of GCNIS shown in percentage of nonmalignant human testis in the sample, hESC, and NT. (D) mRNA expression level of FGF23 in NT, hESC, and NTera2 cells ( $n=1-5)$. (E) IHC staining of GCNIS with adjacent NT, EC, and SEM. Scale bars correspond to $250 \mu \mathrm{m}$ (upper picture) and $100 \mu \mathrm{m}$ (lower picture). (F) Western blot of iFGF23 and cFGF23 in NT, GCNIS, Ana. SEM, EC, NTera2 cells, and TCam2 cells. (G) Levels of seminal iFGF23 or total FGF23 (iFGF23 + cFGF23) in healthy men or men with GCNIS or EC. Parentheses on the $x$-axis indicate sample size. Data are presented as mean \pm SEM. ${ }^{*} p<0.05,{ }^{*} p<0.01,{ }^{*} * * p<0.0001$. Correlations indicated by $R^{2}$. 


\section{Figure 2}
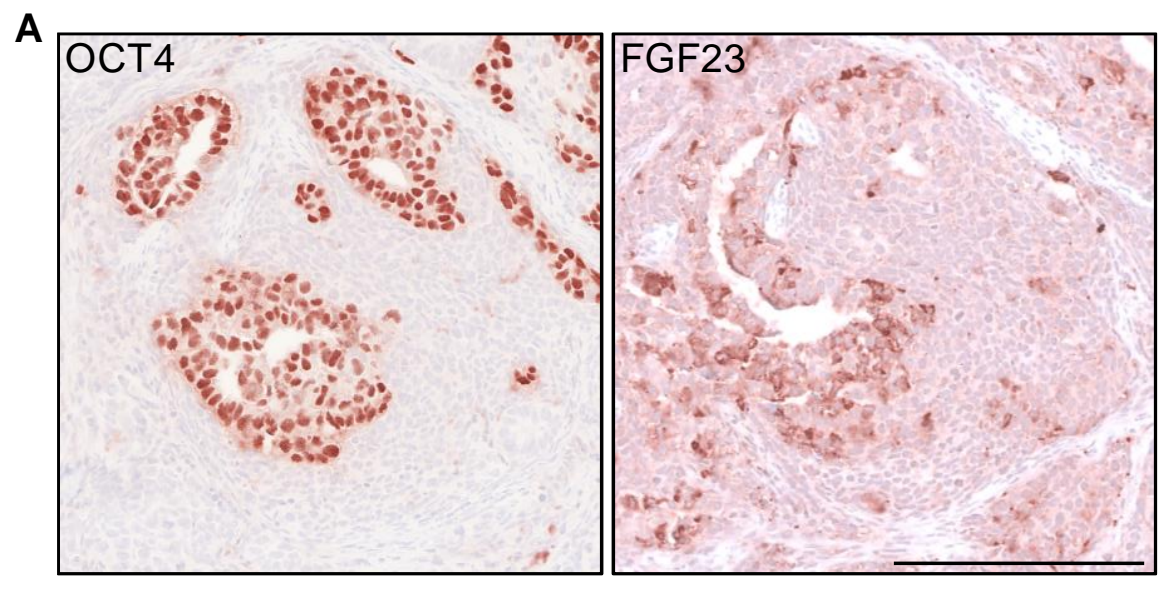

B

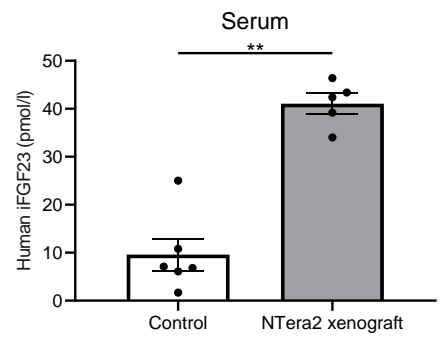

D

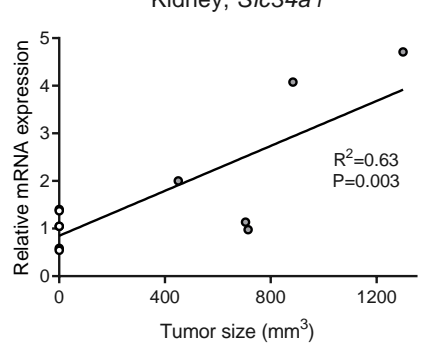

C

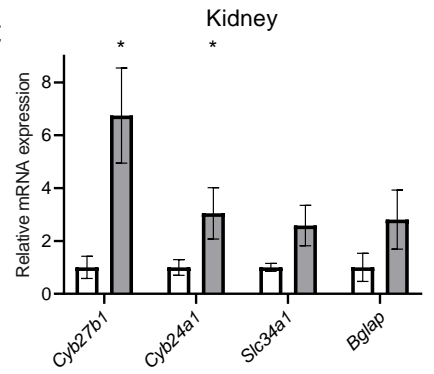

Testis, Slc34a1

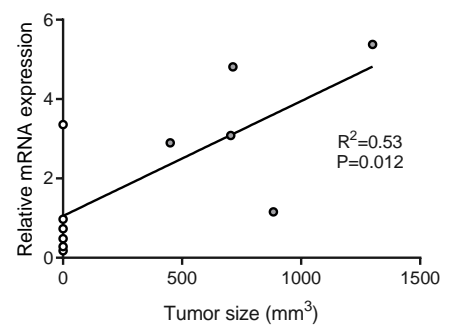

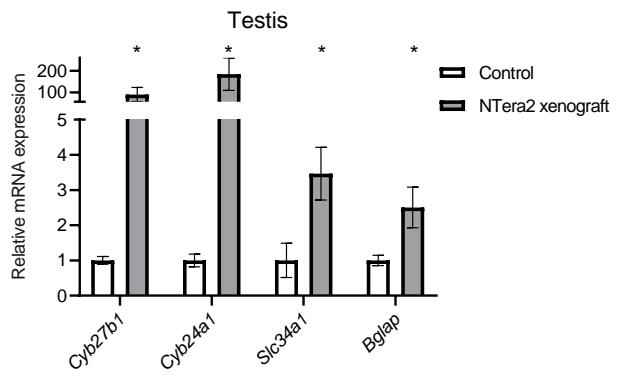

Vitamin D and phosphate homeostasis in kidney and testis of FGF23 producing NTera2 tumor xenografted mice. (A) IHC staining of OCT4 and FGF23 in the tumor on the flank of the nude mice. Scale bar corresponds to $250 \mu \mathrm{m}$. (B) Levels of human iFGF23 in serum of control or NTera2 cell inoculated nude mice. $n=5-6$. (C) mRNA expression level of vitamin D processing enzymes (Cyb27b1 and Cyb24a1), the phosphate transporter S/c34a1, and the bone marker Bglap in testis and kidney of control or NTera2 cell inoculated nude mice. $n=5-6$. (D) Correlations between tumor size and mRNA expression of SIc34a1 in kidney and testis of vehicle or NTera2 cell xenografted nude mice. $n=11$. Data are presented as mean \pm SEM. ${ }^{*} p<0.05,{ }^{* *} p<0.01$. Correlations are indicated by $\mathrm{R}^{2}$. 


\section{Figure 3}

A

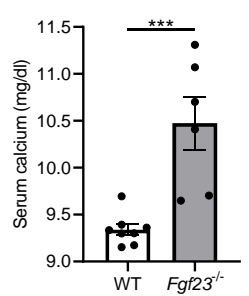

B

\begin{tabular}{lcc}
\hline Protein & WT & Fgf23 $^{-/-}$ \\
\hline BGALP & $1 / 6$ & $4 / 4$ \\
DMP1 & $1 / 4$ & $4 / 4$ \\
OPN & $2 / 5$ & $2 / 2$ \\
\hline
\end{tabular}

C

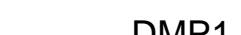$$
{ }_{\text {WT }} \text { Fgtro }^{-}
$$
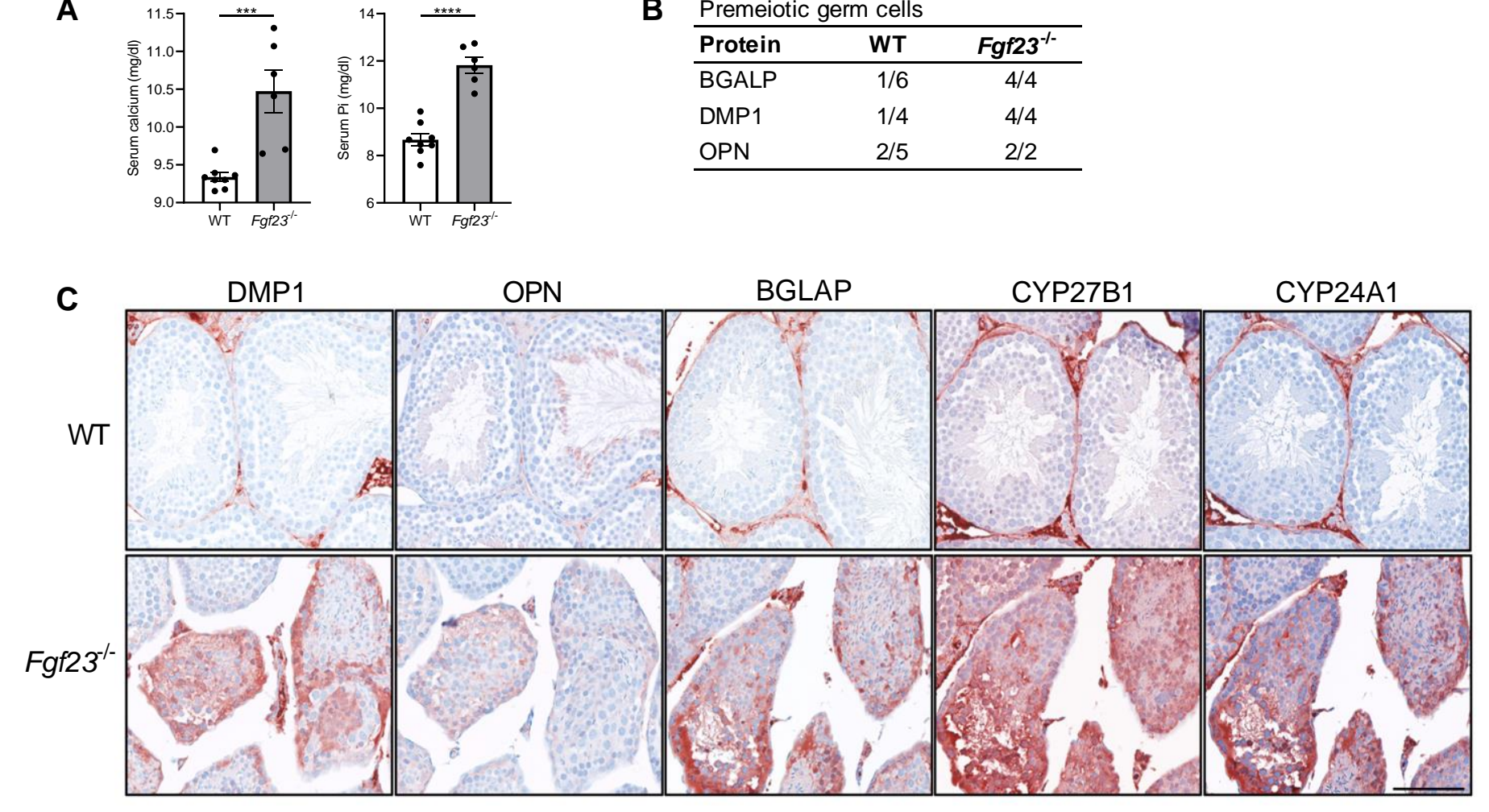

D Epididymis

\begin{tabular}{lcc}
\hline Protein & WT & Fgf23 $^{-/ \text {- }}$ \\
\hline BGALP & $0 / 6$ & $4 / 5$ \\
DMP1 & $0 / 4$ & $4 / 5$ \\
OPN & $0 / 6$ & $4 / 5$ \\
\hline
\end{tabular}

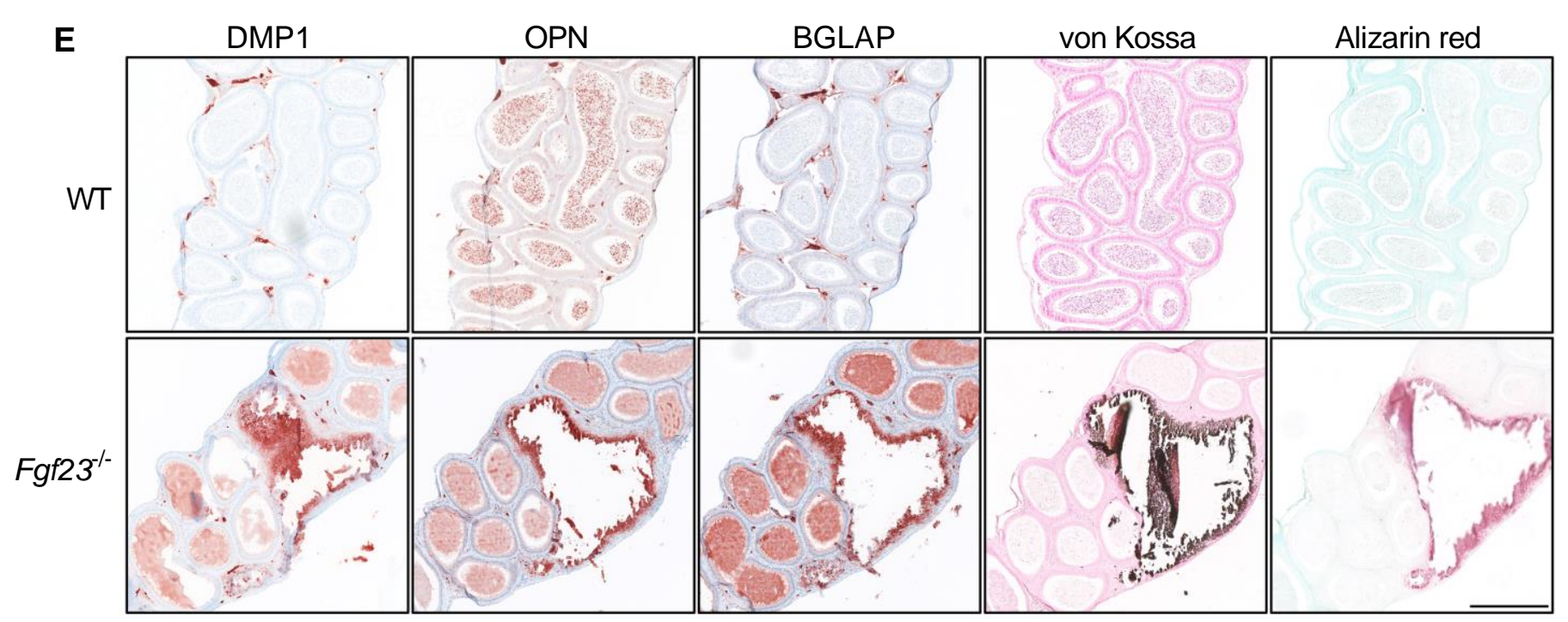

Mineralization in reproductive organs of Fgf23 knockout mice. (A) Levels of serum calcium and Pi in WT and Fgf $23^{-/}$ mice. (B) Table of bone marker expressions in premeiotic germ cells in WT and Fgf $23^{-/-}$mice. (C) IHC staining of bone 
bioRxiv preprint doi: https://doi.org/10.1101/2020.06.25.171355; this version posted June 27, 2020. The copyright holder for this preprint (which was not certified by peer review) is the author/funder. All rights reserved. No reuse allowed without permission.

markers and vitamin D processing enzymes in WT and Fgf23\%- mice. Scale bar corresponds to $100 \mu \mathrm{m}$. (D) Table of bone marker expressions in the epididymis of WT and Fgf $23^{-/-}$mice. (E) IHC staining of bone markers and staining of minerals

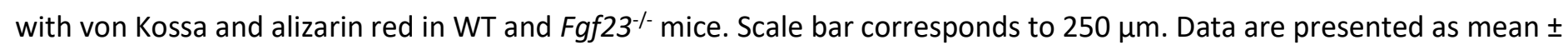
SEM. ${ }^{* * *} p<0.001, * * * * p<0.0001$. 


\section{Figure 4}

A

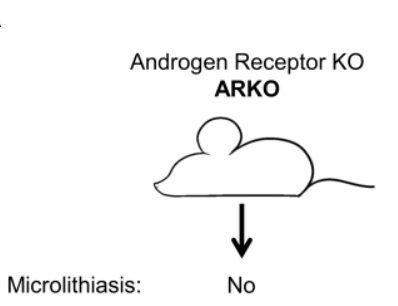

B

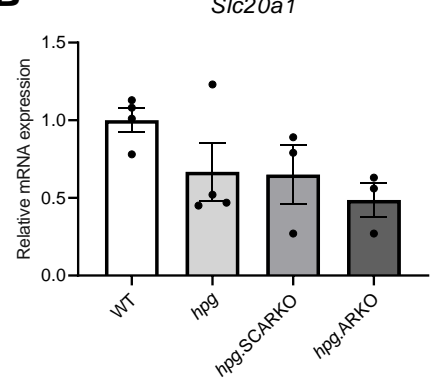

Androgen Receptor $\mathrm{KO}$ in Sertoli cells

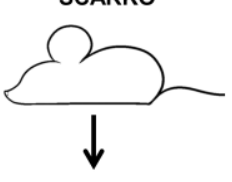

No

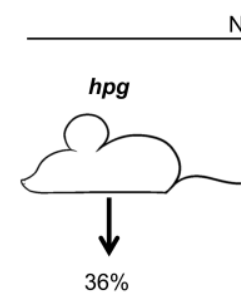

o circulating gonadotrophins
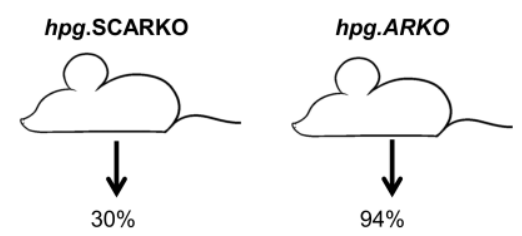

C
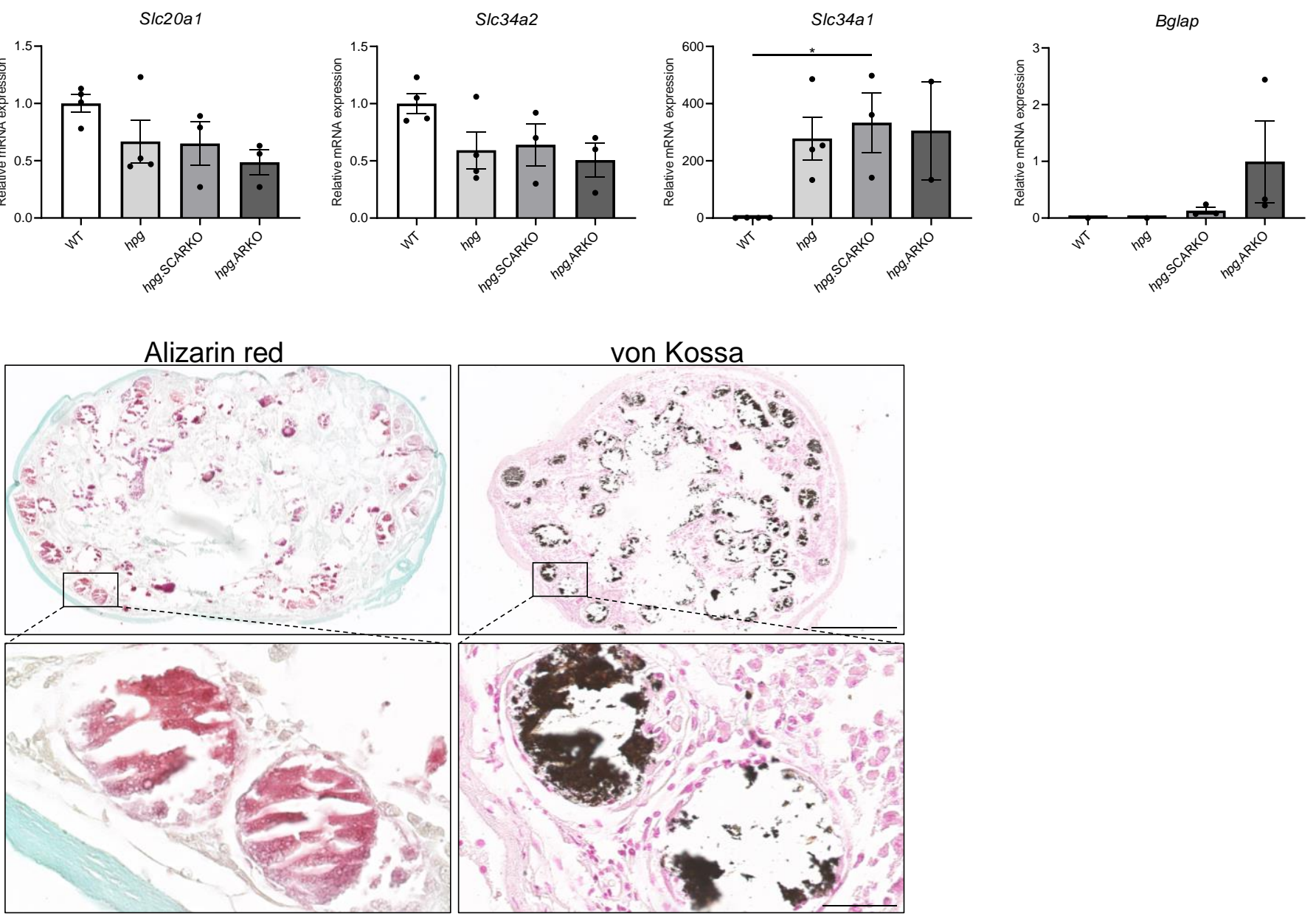

Testicular microcalcifications in hypogonadal and Sertoli cells ablated mice. (A) Schematic representation of the prevalence of microlithiasis in ARKO, SCARKO, hpg, hpg.SCARKO, and hpg.ARKO mice models. (B) mRNA expression levels of S/c20a1, S/c34a2, S/c34a1, and Bglap in testis of $h p g$, hpg.SCARKO, and hpg.ARKO mice models ( $\mathrm{n}=2-4)$. Data are presented as mean \pm SEM. ${ }^{*} p<0.05$. (C) Microcalcifications in Sertoli cells ablated mice. Mineral staining with alizarin red or von Kossa. Scale bars correspond to $500 \mu \mathrm{m}$ (upper pictures) and $50 \mu \mathrm{m}$ (lower pictures). 
bioRxiv preprint doi: https://doi.org/10.1101/2020.06.25.171355; this version posted June 27, 2020. The copyright holder for this preprint (which was not certified by peer review) is the author/funder. All rights reserved. No reuse allowed without permission.

\section{Figure 5}

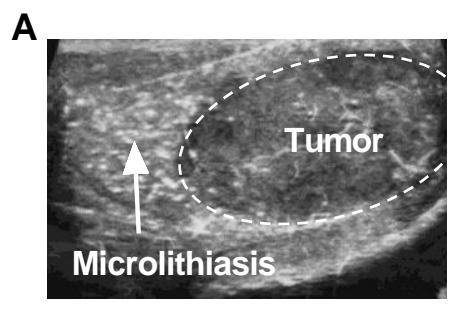

von Kossa

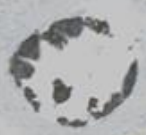

4

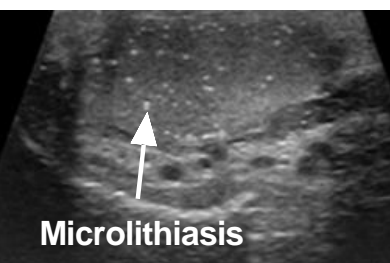

Alizarin red

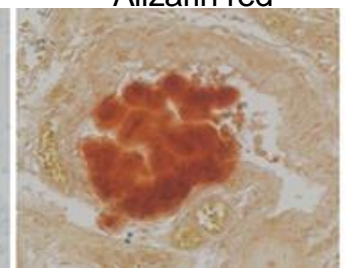

B
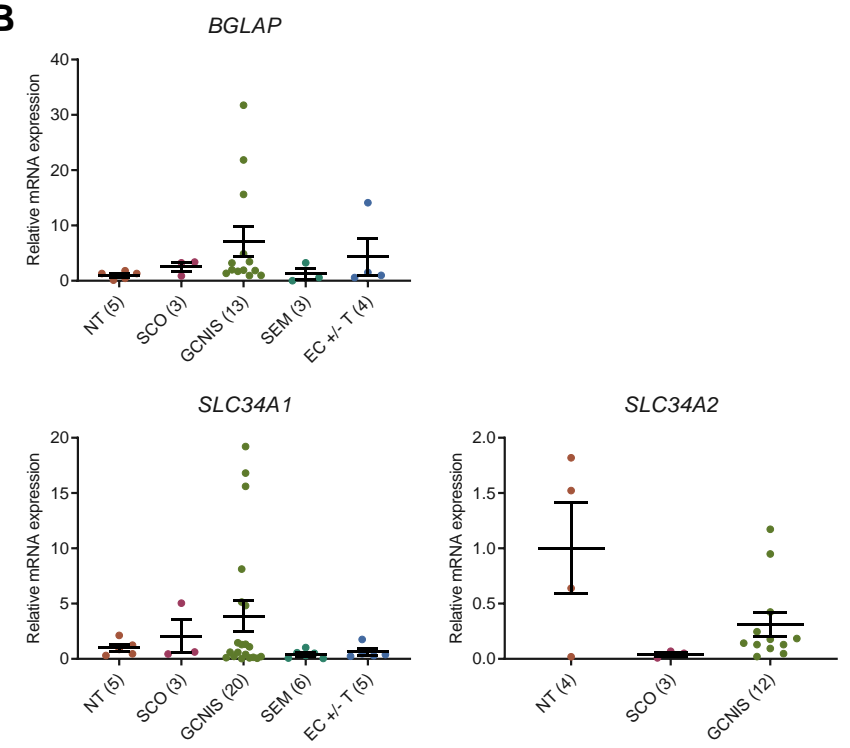

D

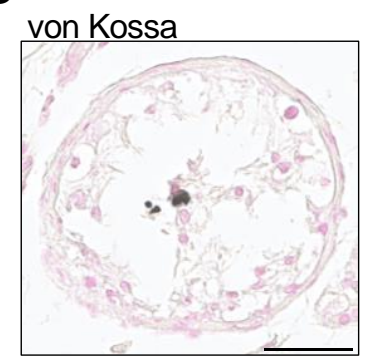

E

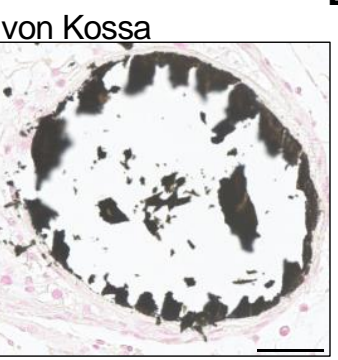

\section{C}
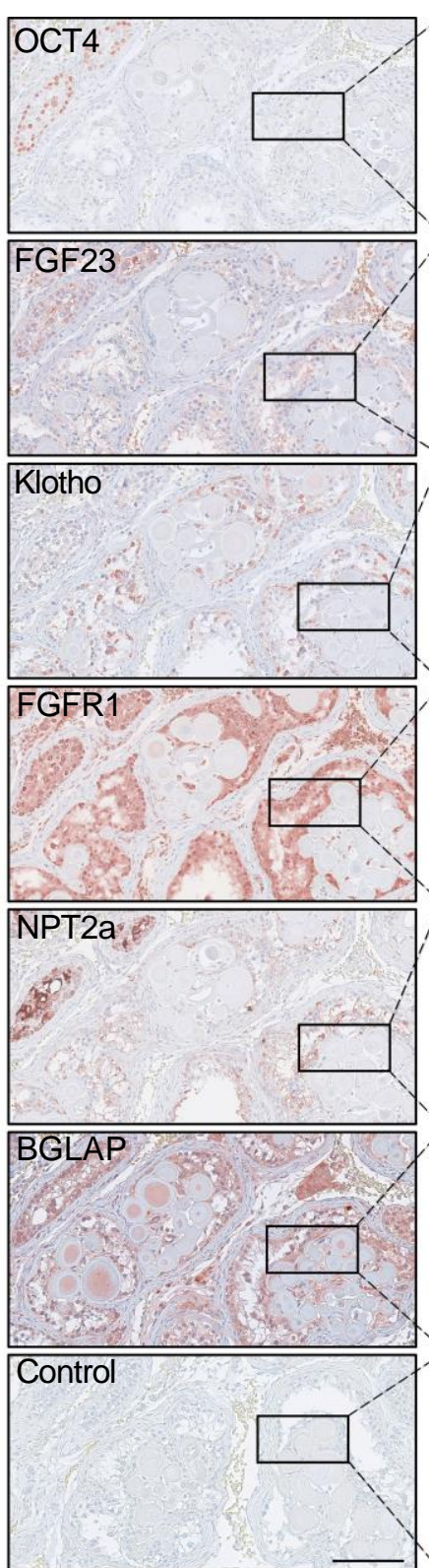
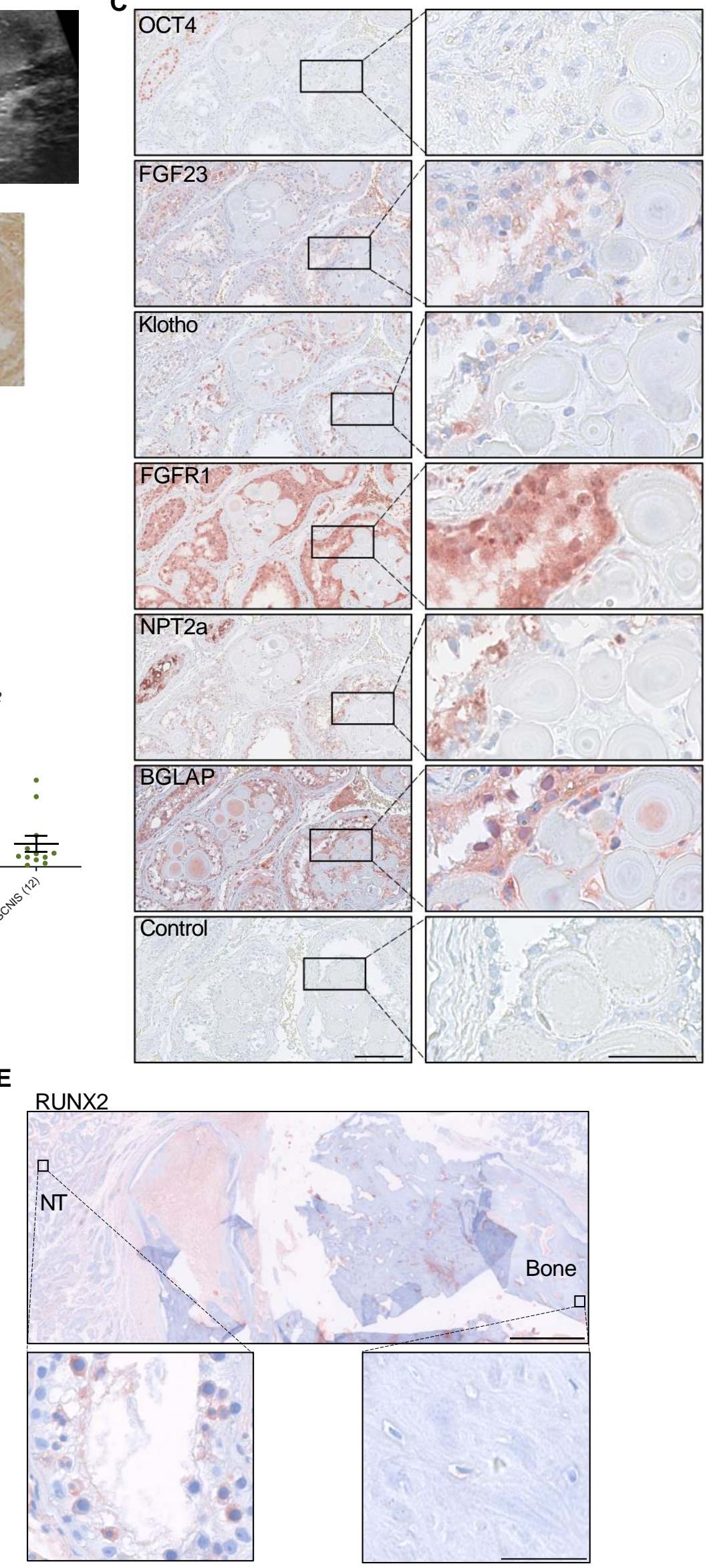
The deposition of hydroxyapatite is linked with the induction of bone markers. (A) Ultrasonic detection of testicular microlithiasis adjacent to a tumor (left) or in an otherwise healthy testis (right). Staining of calcifications by von Kossa and alizarin red. (B) mRNA expression levels of a bone marker (BGLAP) and phosphate transporters (SLC34A1 and SLC34A2) in NT, SCO, GCNIS, SEM, EC +/- T. Data are presented as mean \pm SEM. (C) IHC staining of proteins potentially involved in the formation of testicular microcalcifications adjacent to microcalcifications in human testis. Scale bars correspond to $125 \mu \mathrm{m}$ (left) and $25 \mu \mathrm{m}$ (right). (D) Mild (left) and moderate (right) microcalcifications in human testis stained with von Kossa. Scale bar corresponds to $50 \mu \mathrm{m}$. (E) Severe bone formation in human testis IHC stained with RUNX2. Scale bars correspond to $1.25 \mathrm{~mm}$ (upper), $50 \mu \mathrm{m}$ (lower, left and middle), and $100 \mu \mathrm{m}$ (lower, right). 
bioRxiv preprint doi: https://doi.org/10.1101/2020.06.25.171355; this version posted June 27, 2020. The copyright holder for this preprint (which was not certified by peer review) is the author/funder. All rights reserved. No reuse allowed without permission.

\section{Figure 6}
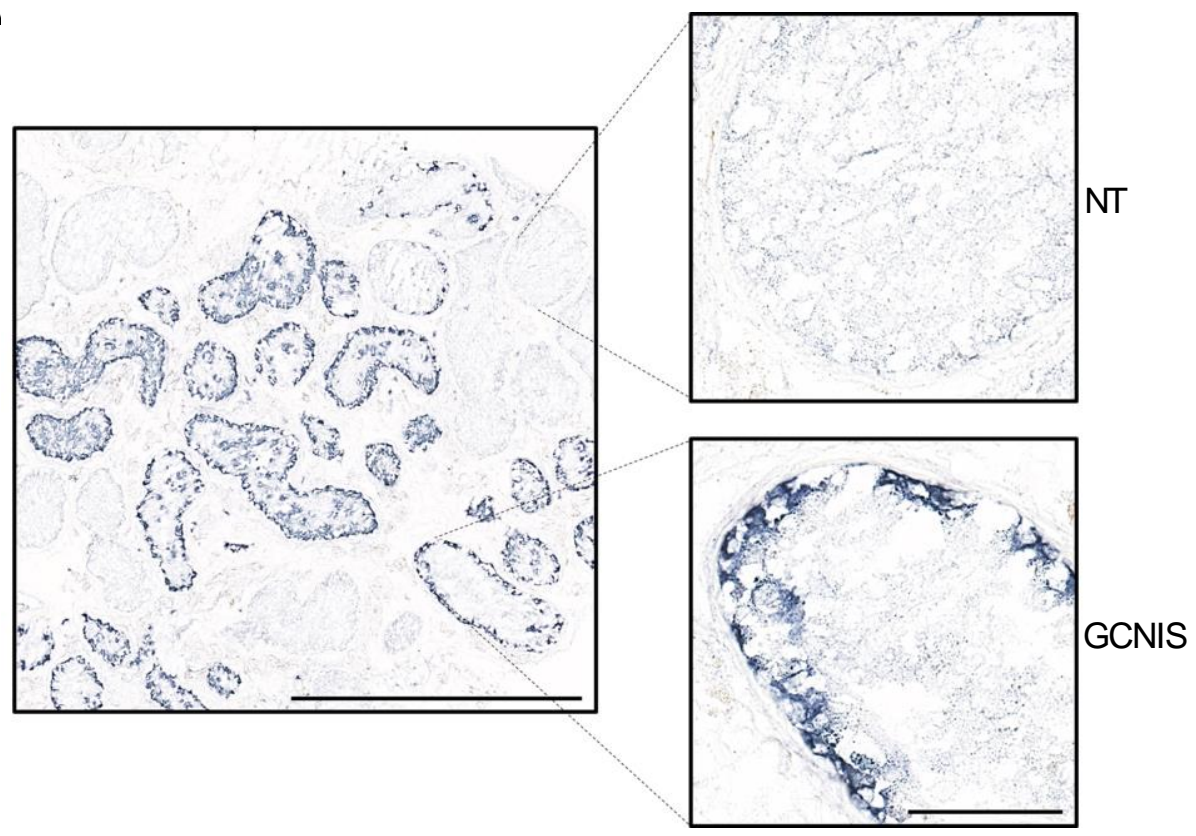

B

D2

D4

D7
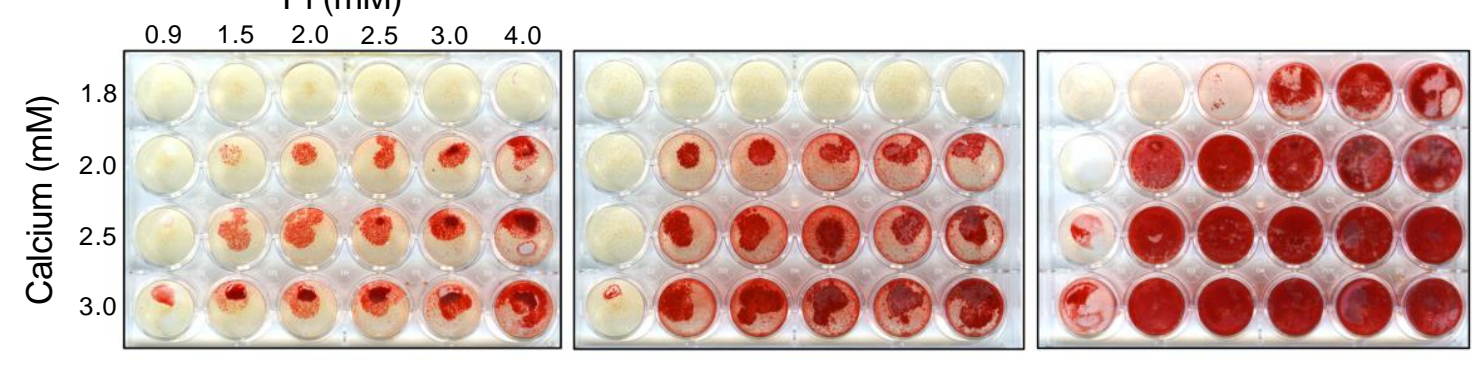

\section{C}
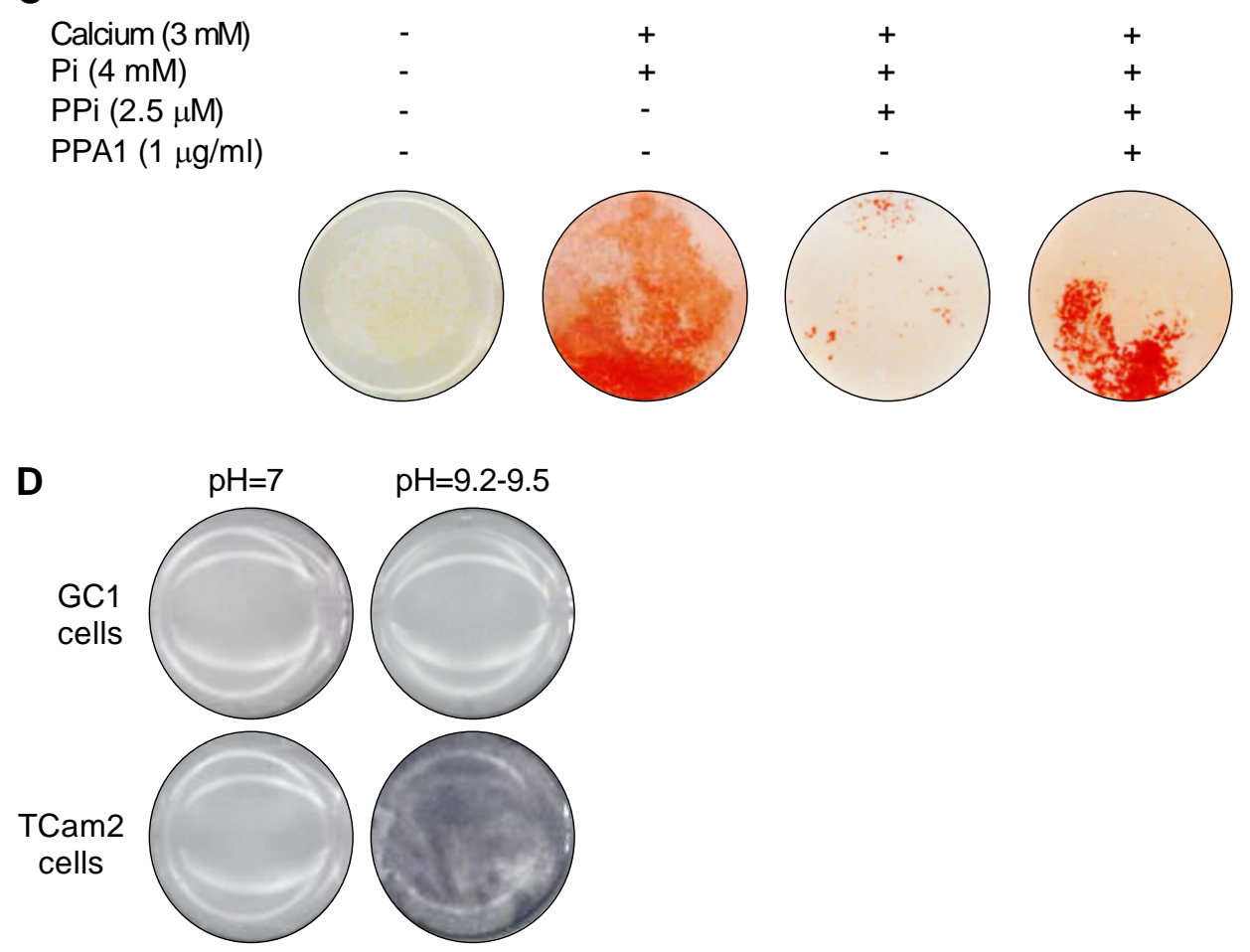
Alkaline phosphatase activity in normal testis and GCNIS and calcium and phosphate induced mineralization in vitro.

(A) BCIP/NBT staining of alkaline phosphatase activity in normal testis (NT) with adjacent GCNIS. Scale bars correspond to $1 \mathrm{~mm}$ (left picture) and $100 \mu \mathrm{m}$ (right pictures). (B) Deposition of hydroxyapatite stained with alizarin red in GC1 cells treated with increasing concentrations of calcium and Pi for 2, 4, or 7 days. (C) Deposition of hydroxyapatite stained with alizarin red in GC1 cells with different treatments for 4 days. (D) BCIP/NBT staining of alkaline phosphatase activity in GC1 or TCam2 cells in $\mathrm{pH}=7$ or $\mathrm{pH}=9.2-9.5$. 
bioRxiv preprint doi: https://doi.org/10.1101/2020.06.25.171355; this version posted June 27, 2020. The copyright holder for this preprint (which was not certified by peer review) is the author/funder. All rights reserved. No reuse allowed without permission.

\section{Supplementary table 1}

Immunohistochemical expression of selected proteins in human specimens

\begin{tabular}{|c|c|c|c|c|c|c|c|}
\hline & $n$ & FGF23 & KLOTHO & FGFR1 & BGLAP & RUNX2 & OPN \\
\hline Normal testis & $7-15$ & $\div$ & ++ to +++ & ++ to +++ & $\div$ & $\div$ & + \\
\hline Germ cell carcinoma in situ & $6-18$ & +++ & $\div$ to $+/-$ & ++ to +++ & + & +++ & + \\
\hline Hyalinized/calcified testis & $5-14$ & $\div$ to + & $+/-$ to + & ++ & +++ & +++ & +++ \\
\hline Classical seminoma & $4-15$ & $\div$ to + & $\div$ & ++ & $\div$ & $\div$ & $\div$ \\
\hline Anaplastic seminoma & 2 & ++ & $+/-$ & ++ & N.A. & N.A. & N.A. \\
\hline Embryonal carcinoma & $4-13$ & ++ to +++ & $\div$ to $+/-$ & ++ & $+/-$ to ++ & $+/-$ to + & $+/-$ to + \\
\hline Teratoma & $3-6$ & $\div$ to + & $+/-$ to ++ & ++ & $+/-$ to ++ & +/- to + & $+/-$ to + \\
\hline Fetal testis & 3 & $\div$ to $+/-$ & $\div$ & ++ & N.A. & N.A. & N.A. \\
\hline
\end{tabular}

$\div \quad$ Not expressed

+ +/- Barely detectable in few cells

$+\quad$ Expressed in few cells

$+\quad$ Markedly expressed in some cells or expressed in most cells

$++\quad$ High expression in most cells

N.A. Not available 
bioRxiv preprint doi: https://doi.org/10.1101/2020.06.25.171355; this version posted June 27, 2020. The copyright holder for this preprint (which was not certified by peer review) is the author/funder. All rights reserved. No reuse allowed without permission.

\section{Supplementary table 2}

List of primary antibodies used for IHC staining.

\begin{tabular}{lllll}
\hline Antibody & Catalog no. & Manufacturer & Dilution & Buffer \\
\hline BGLAP & sc-30044 & Santa Cruz biotechnology & $1: 50 / 1: 100$ & CIT \\
CYP24A1 & sc-66851 & Santa Cruz biotechnology & $1: 500$ & CIT \\
CYP27B1 & sc-67261 & Santa Cruz biotechnology & $1: 100$ & CIT \\
DMP1 & sc-73633 & Santa Cruz biotechnology & $1: 100$ & TEG \\
FGF23 & sc-16849 & Santa Cruz biotechnology & $1: 75 / 1: 200$ & TEG \\
FGFR1 & sc-33928 & Santa Cruz biotechnology & $1: 500$ & TEG \\
Klotho & sc-22220 & Santa Cruz biotechnology & $1: 100 / 1: 200$ & TEG \\
MAGE & Gift from Prof. Spagnoli & Non-commercial & $1: 500$ & TEG \\
NPT2a & sc-33928 & Santa Cruz biotechnology & $1: 200$ & TEG \\
OCT4 & sc-5279 & Santa Cruz biotechnology & $1: 50 / 1: 100$ & TEG \\
OPN & sc-73631 & Santa Cruz biotechnology & $1: 100$ & CIT \\
PLAP & M7191 & Abcam & $1: 100$ & CIT \\
RUNX2 & sc-10758 & Santa Cruz biotechnology & $1: 400$ & TEG \\
SOX9 & AB5535 & Merck Millipore & $1: 400$ & TEG \\
\hline
\end{tabular}


bioRxiv preprint doi: https://doi.org/10.1101/2020.06.25.171355; this version posted June 27, 2020. The copyright holder for this preprint (which was not certified by peer review) is the author/funder. All rights reserved. No reuse allowed without permission.

\section{Supplementary table 3}

List of primers used for quantitative qPCR

\begin{tabular}{|c|c|c|}
\hline Gene & Forward primer & Reverse primer \\
\hline \multicolumn{3}{|c|}{ Human } \\
\hline$B 2 M$ & ATCCAATCCAAATGCGGCATC & AGTATGCCTGCCGTGTGAAC \\
\hline$B G L A P$ & САCTCCTCGCCCTATTGGC & GTGGTCAGCCAACTCGTCA \\
\hline FGF23 & CACCTGCAGATCCACAAGAA & TAATCACCACAAAGCCAGCA \\
\hline NANOG & TGATTTGTGGGCCTGAAGAAAA & GAGGCATCTCAGCAGAAGACA \\
\hline OCT4 & GACTCCTCGGTCCCTTTCC & CAAAAACCCTGGCACAAACT \\
\hline SLC34A1 & CCCTCAGGTCCTACACAGGAT & GGAGCAGACGAAGAGGTAGAG \\
\hline SLC34A2 & CTGAGGCACCTGTAACCAAGA & GGAGCACACGAAAAAGTAGAGA \\
\hline \multicolumn{3}{|c|}{ Mouse } \\
\hline$B 2 m$ & CGAGACATGTGATCAAGCATCA & TATTGCTCAGCTATCTAGGATAT \\
\hline Bglap & CTGACCTCACAGATCCCAAGC & TGGTCTGATAGCTCGTCACAAG \\
\hline Cyp24a1 & ACACTGGCAGAGTACCACAAG & TCCAGGGTTTGATCTCTAGCC \\
\hline Cyp27b1 & GCACAGTTTACGTTGCCGAC & CGTTAGCAATCCGCAAGCA \\
\hline Slc20a1 & TCATCATTGCATTTGTCTTGGCA & CGGATGGTTTCGCTCACTTTG \\
\hline Slc34a1 & GACAATGCCATCCTATCCAACC & GAGCCCATGATGATCGGAATG \\
\hline Slc34a2 & GACTGAACTGCTACCCTCCTA & ACCATTTGATCCCAGTGTCCT \\
\hline
\end{tabular}




\section{Supplementary figure 1}

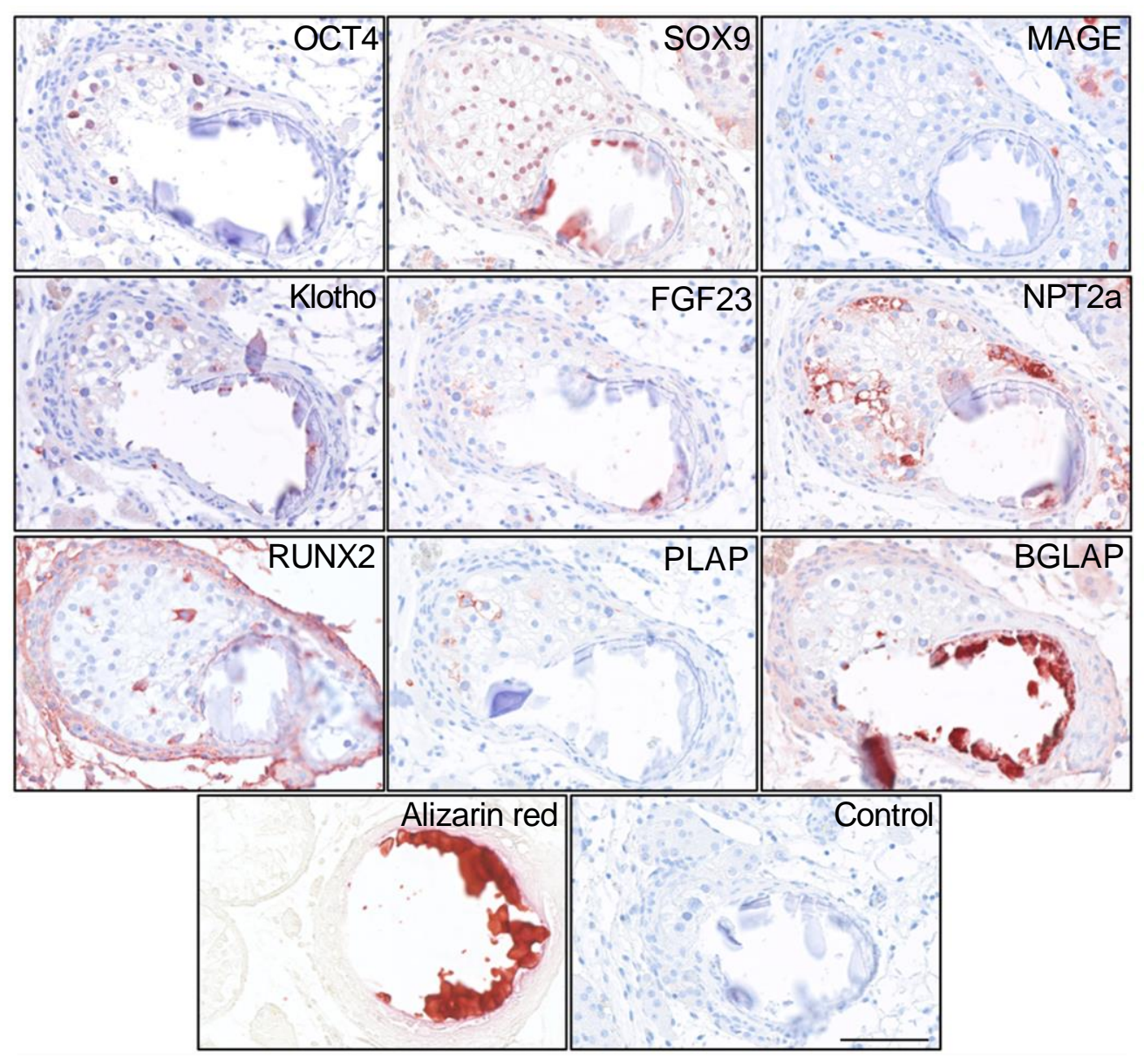

Deposition of hydroxyapatite and bone markers. IHC staining of proteins potentially involved in the formation of testicular microcalcifications adjacent to microcalcifications in human testis. Scale bar corresponds to $100 \mu \mathrm{m}$. 
bioRxiv preprint doi: https://doi.org/10.1101/2020.06.25.171355; this version posted June 27, 2020. The copyright holder for this preprint (which was not certified by peer review) is the author/funder. All rights reserved. No reuse allowed without permission. 